Please do not remove this page

RMIT

UNIVERSITY

\title{
In situ nanoindentation: probing nanoscale multifunctionality
}

Nili Ahmadabadi, Hussein; Kalantar Zadeh, Kourosh; Bhaskaran, Madhu; Sriram, Sharath

https://researchrepository.rmit.edu.au/esploro/outputs/9921858295401341/filesAndLinks?institution=61 RMIT_INST\&index=null

Nili Ahmadabadi, H., Kalantar Zadeh, K., Bhaskaran, M., \& Sriram, S. (2013). In situ nanoindentation: probing nanoscale multifunctionality. Progress in Materials Science, 58(1), 1-29.

https://doi.org/10.1016/j.pmatsci.2012.08.001

Published Version: https://doi.org/10.1016/j.pmatsci.2012.08.001

Repository homepage: https://researchrepository.rmit.edu.au

(c) 2012 Elsevier Ltd. All rights reserved.

Downloaded On 2023/04/26 23:43:46 +1000

Please do not remove this page 
Thank you for downloading this document from the RMIT Research Repository.

The RMIT Research Repository is an open access database showcasing the research outputs of RMIT University researchers.

RMIT Research Repository: http://researchbank.rmit.edu.au/

\section{Citation:}

Nili Ahmadabadi, H, Kalantar Zadeh, K, Bhaskaran, M and Sriram, S 2013, 'In situ nanoindentation: probing nanoscale multifunctionality', Progress in Materials Science, vol. 58, no. 1, pp. 1-29.

See this record in the RMIT Research Repository at:

http://researchbank.rmit.edu.au/view/rmit:16990

Version: Submitted Version

Copyright Statement: ㄷ 2012 Elsevier Ltd. All rights reserved.

Link to Published Version:

http://dx.doi.org/10.1016/j.pmatsci.2012.08.001 


\title{
In situ nanoindentation: Probing nanoscale multifunctionality
}

\author{
Hussein Nili, Kourosh Kalantar-zadeh, Madhu Bhaskaran,* and Sharath Sriram* \\ Functional Materials and Microsystems Research Group, RMIT University, GPO Box 2476, \\ Melbourne, Victoria 3001, Australia \\ * Corresponding authors. Tel.: +61 3 99250440; fax: +61 3 99253242. E-mail: \\ madhu.bhaskaran@gmail.com (M. Bhaskaran), sharath.sriram@gmail.com (S. Sriram).
}

\begin{abstract}
Nanoindentation is the leading technique for evaluating nanoscale mechanical properties of materials. Consistent developments in instrumentation and their capabilities are transforming nanoindentation into a powerful tool for characterization of multifunctionality at the nanoscale. This review outlines the integration of nanoindentation with real-time electron imaging, high temperature measurements, electrical characterization, and a combination of these. In situ nanoindentation measurements have enabled the real-time study of the interplay between mechanical, thermal, and electrical effects at the nanoscale. This review identifies previous reviews in this area, traces developments and pinpoints significant recent advances (post-2007), with emphasis on the applications of in situ nanoindentation techniques to materials systems, and highlighting the new insights gained from these in situ techniques. Based on this review, future directions and applications of in situ nanoindentation are identified, which highlight the potential of this suite of techniques for materials scientists from all disciplines.
\end{abstract}

Keywords: nanoindentation, in situ techniques, electron microscopy, SEM, TEM, heating, electrical, thin films, nanoscale properties, nanomechanics 


\section{INTRODUCTION}

Nanoscale characterization techniques are continuously challenged by the rapid progress in nanostructures and functional materials demanding higher resolutions and advanced measurement techniques for mechanical, chemical, electrical, and thermal

5 characterization. Numerous techniques have been developed over the years for the characterization of materials at the nanoscale, the most notable of which are electron microscopy [1-6], scanning probe or atomic force microscopy [7-15], X-ray imaging [3,5,16-21], and nanoindentation [22,23]. A recent review by Robertson et al. [24] provides a detailed overview of nanoscale materials characterization techniques.

With the exception of transmission electron microscopy (TEM), which has managed to reach a lateral resolution limit in the order of a few angstroms and a few recent claims of sub-angstrom [6], far-field probing methods including optical and electron microscopy and spectrometry techniques cannot match the resolution of nearfield probing (direct contact physical processes such as scanning probe microscopy).

15 However, the combination of near and far-field approaches, provides even more powerful techniques for nanoscale characterization of materials.

Amongst the wide variety of characterization techniques, nanoindentation is the most rigorous approach for quantitative characterization of nanoscale mechanical properties of materials (bulk and thin film form) [22,23]. To the uninitiated, 20 nanoindentation can be likened to pricking the surface of the material with a very sharp pin, and studying the process and effect of this pin prick. The forces used for nanoindentation vary from a few micro-Newtons $(\mu \mathrm{N})$ to a few milli-Newtons $(\mathrm{mN})$, and considering the tip-surface interaction areas under consideration (a few $n m^{2}-\mu m^{2}$ ) this can easily translate into immense values of pressure. The information gained from 
this process is used to determine the Young's modulus and hardness of a material in the most basic form; however, this information can also be used to understand formation and propagation of mechanically-induced dislocations and defects. The study of the nanoindentation response of materials in combination with real-time imaging, heating, 5 and/or electrical measurements in situ can create a broader understanding of the behavior of materials at the nanoscale. This understanding will be valuable in supporting the impetus to harness multifunctionality of materials to realize smart nanoand micro-devices.

In the past decade, a few reviews have been published on different and specific 10 aspects of nanoindentation. Oliver and Pharr, who have played a leading role in presenting models for quantitative nanoindentation, have presented a general overview on the development and recent advances of nanoindentation techniques [22]. However, the last review on in situ nanoindentation was in 2006 by Schuh [25], which provided an excellent overview of in situ techniques with particular emphasis on technological 15 advancements.

Our review traces the progress of in situ nanoindentation techniques, by creating a time-line from the first experiments, through refinements, to today's state-of-the-art systems and approaches. The aim is to provide the reader with a broad insight into the versatile processes, the spectrum of materials insight that can be garnered, and arm them 20 with a comprehensive catalogue of references. In comparison to the review by Schuh [25], our work places specific emphasis on applications of in situ nanoindentation to different materials systems covering significant developments in the last 5 years (highlighted by $>80$ references being from 2007 onwards). 
This review is presented in the form of five main sections. Section II provides a background to nanoindentation, identifies literature pertaining to mechanical processes, and discusses the types of tips/probes utilized for nanoindentation. Sections III to V provide a detailed discussion of the development and applications of nanoindentation in

5 combination with real-time electron imaging, heating, and electrical measurements, respectively. Each of these detailed sections (III to V) are categorized by materials systems, with the intention to allow readers to easily access content of relevance and appreciate the wide spectrum of capabilities of the in situ nanoindentation approach. Section VI discusses two examples, both from 2011, where more than one in situ 10 characterization process during nanoindentation have been combined, and the extremely valuable scientific insight gained.

\section{BACKGROUND}

\section{2.1. Nanoindentation - nanomechanics and early in situ measurements}

Nanoindentation was introduced as a method for determining the modulus and hardness of materials in 1992 [26], by studying nanomechanical response as a function of penetration depth. This method has been constantly refined, with additional capabilities for mapping and control included, which has enabled the determination of 20 other nanoscale mechanical phenomena. Nanoindentation is widely used to study the displacement $(h)$ of materials under specific applied loads $(P)$ to produce loaddisplacement $(P-h)$ curves. Anomalies in these curves relate to mechanical phenomena such as the onset of dislocations, cracks, and even crystalline phase transformations. 
The developments of nanoindentation from a perspective of nanomechanical characterization is presented in a recent review by Oliver and Pharr [22].

The potential to harness the nanoscale probing capabilities of nanoindentation in versatile applications, besides just modulus and hardness measurements, resulted in development of in situ nanoindentation techniques. Some of the earliest developments in in situ nanoindentation focused on visualizing the mechanical process in real-time using electron microscopes [27,28]. This review discusses such developments briefly, but focuses on the applications of in situ nanoindentation to different materials systems, with the aim of presenting its contributions to progress in materials science.

\subsection{Nanoindentation tips - types and selection}

The process of nanoindentation and subsequent interpretation of mechanical response depends on the hardness and geometry of the tip or probe used to perform indentation. This section outlines the basic tip geometries, tip selection for different

15 materials, and highlights the use of tips primarily as nanoscale probes in in situ characterization. Standard indenter tip geometries can be categorized as 3- and 4-sided pyramidal tips such as Berkovich, Vickers, cube-corner tips, and basic geometries such as conical and spherical tips. A variety of shapes and geometries for specific applications are available from manufacturers. While the choice of the tip is critical for 20 accurate quantification of nanoindentation results, in the context of this review, modifications to tips have proven to be vital in enabling in situ nanoindentation.

Nanoindentation experiments are predominantly carried out using the Berkovich tip, which is a three-sided pyramid with a face half-angle of $65.27^{\circ}[29,30]$. Other tip geometries such as four-sided pyramids (the Vickers indenter), wedges, cones, 
cylinders, and spheres are also used but not as often. The reason for using Berkovich over others tips is that it maintains a self-similar geometry to very small scales and gives the sharpest tip achievable (down to a few nanometers) with such geometries, while giving the same projected area as the four-sided Vickers indenter used in 5 microindentation tests. This maximized tip sharpness makes the Berkovich geometry most suited for localized, nanoscale indentation experiments. Moreover, the Berkovich tip allows the measurement of plasticity at very small loads and minimizes the effect of friction due to its large face angle.

With respect to applications, Berkovich tips are primarily used for the indentation 10 of bulk materials and thin films greater than $100 \mathrm{~nm}$ in thickness. Cube corner probes have a sharper tip than Berkovich probes, and therefore, are ideal for the indentation of ultra-thin samples where the plastic deformation must be confined to a smaller volume and for high resolution in situ imaging. Conical and spherical tips are most widely used for the indentation of soft polymers and MEMS structures, generally to complement or 15 compare with Berkovich indentation results. Due to their geometry, the more-rounded conical and spherical tips cannot achieve a radius of curvature as confined as the threesided pyramid. For the indentation of very soft materials like polymers and biological samples, very blunt conical tips are used. Other specialty probes and tips have also been developed to conduct nanoindentation experiments in a variety of environments such as 20 high temperature and aqueous environments.

In most cases the nanoindenter tip is made out of diamond due to its high hardness and elastic modulus, as well as exceptional thermal conductivity and chemical inertness which enables accurate quantitative measurements on the samples. Other materials such 
as sapphire, quartz, silicon, tungsten, steel, and tungsten carbide are also used as indenter tips for specific applications.

Electrical characterization during nanoindentation testing is highly desirable for studying electromechanical coupling, semiconductor phase transformations, and

5 pressure-induced phenomena in piezoelectric materials at the nanoscale. For this purpose a variety of conductive indenter tips have been developed over the years using stainless steel, tungsten, tungsten carbide and cobalt alloys (WC-Co), and conductive diamond. Initially, the electrical indentation tests were performed using stainless steel tips, before progressing to WC-Co spherical indenters. Boron-doped conductive 10 diamond tips are now used widely to acquire information on electrical properties of the materials during in situ indentation, along with load-displacement data [31]. However, the boron-doped tips suffer from nonuniformities in conductivity due to clustering of dopants, resulting in uniformly conductive vanadium carbide (VC) tips for in situ electrical nanoindentation where extremely high tip hardness is not a requirement. In all

15 these cases of nanoelectromechanical characterization, the conductive tips serve as mechanical probes and electrical top electrodes.

\section{REAL-TIME ELECTRON IMAGING OF NANOINDENTATION}

20 PROCESSES

The nucleation and propagation of dislocations and defects is one of the critical aspects of insight gained from nanoscale characterization by nanoindentation. On this basis, early emphasis of in situ nanoindentation was placed on the ability to image the 
mechanical processes in real-time to observe changes and correlate observations with measured load-displacement curves.

Varied approaches for mechanical testing (at macro-, micro-, and nano-scales) in electron microscopes are presented by Legros et al. [32], with a recent review by Carlton and Ferreira describing technological challenges [33]. In the following section, we focus on nanoscale indentation testing during electron microscopy, and the insight gained by combining the nanoindentation process with real-time imaging.

\subsection{Scanning electron microscopy}

Scanning electron microscopy (SEM) is the most extensively used electron microscopy technique for imaging materials and surfaces at the micro-scale, and increasingly at the nano-scale though advances with field emission sources. The ability to observe nanoindentation induced deformations in real-time using a SEM provides valuable illustrative insight into materials behavior at the micro- and nano-scale. This

15 enables the correlation of load-displacement data from nanoindentation tests with microstructural changes. The promise of such enhanced insight has driven the development of a nanoindentation system compatible with SEM, with these developments encountering challenges due to the fundamental limitations imposed by the microscope, in terms of space and electron detection [34].

\subsubsection{Early developments with transition metal nitride thin films}

One of the first examples of an in situ SEM nanoindentation system was reported by Rabe et al. [35]. In this work, a custom-made nanoindentation and nanoscratch system which allowed real-time SEM observations during nanoindentation tests was 
developed. To demonstrate the potential of the system, nanoindentation and nanoscratch tests were performed on layered titanium nitride and silicon nitride $\left(\mathrm{TiN} / \mathrm{SiN}_{\mathrm{x}}\right)$ coatings and diamond-like carbon (DLC) films. Electron micrographs collected at various points during the indentation process of the $\mathrm{TiN} / \mathrm{SiN}_{\mathrm{x}}$ films, as shown in Fig. 1, provided 5 insight into nanomechanical processes such as cracks and pile-ups and their dependence on penetration depth. As indicated in Fig. 1, each point on the load-displacement curve can be correlated to observed microstructural changes.

A similar approach was utilized to study transformations in zirconium-based bulk metallic glasses [36,37]. These studies examined the onset of fracture, plastic 10 deformations, and instabilities during plastic deformations. In the first study [36], the plastic deformation behavior revealed the formation of shear-bands in the glasses even with the absence of pop-in events (anomalies or kinks) in load-displacement $(P-h)$ data. This result provided visual evidence of the correlation between displacement bursts and shear-band activities. In the second study of these zirconium-based bulk metallic glasses 15 [37], the in situ SEM indentation experiment was further refined to undertake a detailed examination of this shear-band formation process. The refinement involved altering the imaging window and tracking the tip, to greatly enhance the time-resolved observation of discrete events. This work provided an understanding of the influence of the growth process of the glasses on displacements burst in the $P-h$ curves. In situ nanoindentation 20 identified the proclivity of shear-bands to form at locations which underwent a previous shear process. These insights could not have been gained without this direct visualization of the nanoindentation process producing shear bands.

Rzepiejewska-Malyska et al. [38] reported the development of depth-sensing instrumentation capable of in situ SEM nanoindentation (Fig. 2), and demonstrated the 
functionality of this technique with experimental studies on aluminum and gold thin films. They further utilized this technique to study the deformation mechanisms of nitride coatings on silicon substrates: single layers of TiN and chromium nitride $(\mathrm{CrN})$, and multilayers of the two materials [39]. In this work, the in situ nanoindentation 5 studies revealed a series of new mechanical phenomena in TiN. These phenomena included light pile-ups, radial cracks nucleated during loading, as well as adhesive and cohesive failure at higher loads. The research team carried out further comprehensive investigation on the deformation and fracture mechanisms of these multilayered transition metal nitride coatings [40]. In situ observations were correlated with load10 displacement data to carefully evaluate the deformation process of the coatings. In particular, the contact area calculated directly from the SEM image (taken while the tip was under maximum load) differed significantly from the theoretical prediction of the standard Oliver and Pharr [26] approach. This highlights the need to refine theoretical understanding of tip-surface interaction at maximum loads, and reinforces the benefits 15 of in situ imaging during indentation.

\subsubsection{Variations in materials systems and instrumentation}

Following on from the work of Rzepiejewska-Malyska et al. [38-40], Ghisleni et al. [41] presented two in situ SEM-based indentation systems: a microindenter and a

20 PicoIndenter (Hysitron, Inc., USA). The latter system, of interest in this context, was utilized to study electrodeposited cobalt in the form of thin films and nanowires. This work visually depicted that columnar grains in the cobalt thin films undergo bending during compression, with shear effects instead of purely uniaxial compression. While 
providing new insight, this work highlights and identifies challenges in interpreting nanoindentation of the nanowire systems without rigorous modeling/simulation.

In situ SEM nanoindentation was used to evaluate Young's modulus and hardness of yttrium-stabilized zirconia thin films deposited by electron beam physical vapor 5 processes [42]. The real-time observations showed the occurrence of significant elastic structural deformation during the nanoindentation process. It was demonstrated that this would cause an underestimation of the Young's modulus obtained through the Oliver and Pharr [26] method. This work again reinforces the benefits of in situ SEM imaging in order to overcome limitations of theoretical approaches to determine nanomechanical 10 variations.

Direct visualization of the indentation process is not limited to intermetallics and glasses. In situ SEM observations during nanoindentation have been effectively combined with ex situ atomic force microscopy (AFM) imaging and finite element modeling to study elastomeric materials [43]. Polydimethylsiloxane (PDMS) is a

15 popular elastomer utilized in flexible electronics and microfluidics [44]. The SEMbased in situ nanoindentation characterization was used to study deformation and sinkin behaviors and the evolution of tip-elastomer contact surface during the indentation.

\subsubsection{Recent developments with carbon nanomaterials}

In situ SEM nanoindentation has been utilized to understand the nanoscale mechanical properties of carbon-based nanomaterials, especially graphene and nanotubes, given the widespread and current research interest in these materials for reinforced composites [45] and advanced electronics [46]. Of relevance, in a recent study, Huang et al. [46] reported in situ SEM nanoindentation studies of graphene 
devices. The experiments were carried out inside a custom-made instrument (SEMentor) composed of a field-emission gun SEM and a nanomechanical module similar to a nanoindenter. This study was combined with in situ electrical measurements also, and is discussed in detail in Section VI which covers combined in situ techniques.

One of the most illustrative SEM-based nanoindentation experiments was performed on an array of vertically aligned carbon nanotubes (VACNT) [47]. The in situ nanoindentation process was utilized to deform the VACNT array by on-axis compression and the visually observe deformations using the SEM. A series of images collected during the nanoindentation of a $7.5 \mu \mathrm{m}$ VACNT array is shown in Fig. 3. The 10 direct observations enabled new insights into the complex deformation mechanisms of carbon nanotube (CNT) arrays. These results show that only $70 \%$ of the length is effectively deformed and contributes to the load-displacement characteristics. Moreover, the SEM-based observations led to the correlation of deformation mechanics and 'kinks' in the load-displacement curves. For instance, a reduced slope in the stress-

15 strain curves obtained from nanoindentation of a $7.5 \mu \mathrm{m}$ tall VACNT array corresponds to the onset of buckling events in the material [47].

\subsection{Transmission electron microscopy}

The review of in situ SEM nanoindentation above highlights the visual and 20 illustrative impact of the technique. While SEM-based techniques improve understanding of micron and sub-micron effects during the nanoindentation process, they have two major limitations. First, is the inability to view crack propagation through depth of thin films or continuous coatings in the SEM, which is the reason for the most effective studies of nanopillars and nanotube systems. Second, and more significant, is 
the lack of true nanoscale real-time imaging. This relates to observation of stressinduced changes to structure and phase of individual crystals or grains and the ability to study the impact of nanoindentation below and beyond the actual indent region.

The limitations of SEM-based approaches are readily overcome by transmission electron microscopy (TEM), which is currently the most powerful tool for imaging nanostructures and crystals at near atomic resolution. The potential for TEMs to provide true nanoscale images of the nanoindentation process resulted in a concerted effort to develop TEM-based sample holders capable of performing in situ nanoindentation.

\section{3.2.1. Specimen holders for nanoindentation during high energy electron imaging}

Wall and Dahmen $[27,28]$ published the first reports of a sample holder designed for performing nanoindentation and compatible with high energy electron imaging systems. The Wall and Dahmen design was adapted by Stach et al. [48] for compatibility with the widely used JEOL TEMs (Fig. 4). This new nanoindenter and

15 TEM specimen holder was created for a $200 \mathrm{kV}$ JEOL TEM and preliminary characterization of bulk aluminum, titanium carbide, silicon, and aluminum thin films on silicon was carried out. These results demonstrated the ability of the instrumentation to enable high resolution imaging of fractures and dislocations (nucleation, propagation, and interaction). This crucial development opened up opportunities to relate

20 nanomechanical characteristics to atomic effects, dislocation defects in crystals, and even to crystalline transformations under indentation.

Complementary developments on in situ TEM nanoindentation were also reported by Bobji et al. [49,50]. They first developed a novel 3-axis inertial positioner for an in situ TEM nanoindentation specimen holder [50]. This holder was then used to study 
sub-surface deformations taking place in the copper-beryllium alloy system during nanoindentation. While providing visual insight into the nanoindentation mechanics of the alloy, new insight was attained on the effect of the indentation tip roughness on the nucleation of dislocations. It was found that the tip-surface contact region has $\sim 50 \mathrm{~nm}$ 5 sized steps (the roughness an artifact of tip production), with dislocation clusters forming at these points as the tip penetrated the softer copper-beryllium alloy [49].

Utilizing the TEM holder developed for nanoindentation by Stach et al. [48], a broad range of materials in the bulk and thin film forms have been studied. A large volume of the initially reported research outcomes were led by Andrew Minor and 10 colleagues from the University of California at Berkeley. These studies and their results detailed in the following paragraphs played a very significant role in enhancing the capabilities of TEM-based nanoindentation and resulting in this currently popular in situ approach.

\section{3.2.2. Quantitative in situ TEM nanoindentation of metals and alloys}

The first quantitative in situ TEM nanoindentation results were reported for aluminum thin films [51,52]. Aluminum has an inherent softness and low Young's modulus as a result of which clear imprints of the nanoindentation tips can be observed on the material surface. This allows the direct nanoscale observations of deformation

20 mechanisms and incipient plasticity, as well as correlation of onset of plasticity with applied load (Fig. 5). The same approach was applied to examine epitaxial titanium nitride thin films grown on single crystal magnesium oxide (001) substrates [53]. All these results (such as in Fig. 5) highlighted the advantages of real-time nanoscale insight into the deformation mechanisms during nanoindentation and the ability to correlate 
quantified load-displacement data of the nanoindentation test with the underlying deformation mechanisms. Later, a quantitative study to investigate the onset of plasticity and correlate it to dislocation activity in Al was conducted [54]. A capacitive load-displacement transducer was integrated into the TEM holder, permitting high 5 resolution load-displacement response measurements to be directly correlated with realtime diffraction contrast images obtained during nanoindentation test. Most recently, quantitative in situ nano tensile testing in a TEM has been used to study single slip and multiple slip deformation in copper single crystals [55].

Jin et al. [56] have performed in situ TEM nanoindentation studies on ultrafine10 grained $\mathrm{Al}$ thin films, confirming the contribution of nanoscale mechanisms such as deformation-induced grain growth resulting from grain boundary during nanoindentation tests. In a complementary study, Soer et al. [57] compared the behavior of ultrafine-grained $\mathrm{Al}$ and $\mathrm{Al}-\mathrm{Mg}$ thin films through in situ TEM nanoindentation. It was observed that $\mathrm{Mg}$ solutes effectively pin high-angle grain boundaries during the 15 deformation of $\mathrm{Al}$ thin films, revealing insight into the fundamental role of $\mathrm{Mg}$ in the modified properties of Al-Mg alloys over pure Al. An overview of in situ TEM nanoindentation and its applications in studying dislocation-grain boundaries with an emphasis on the deformation characteristics of $\mathrm{Al}$ and $\mathrm{Al}-\mathrm{Mg}$ thin films is presented in a review by De Hosson et al. [58].

20 A combination of in situ nanoindentation with high resolution TEM and inverse fast Fourier transform (FFT) analysis has been used to investigate various types of interface-dislocation interaction in $\mathrm{Al} / \mathrm{Nb}$ multilayers [59]. The TEM micrographs revealed two types of dislocations in these $\mathrm{Al} / \mathrm{Nb}$ multilayers: at interface and inside the 
layers with the density of the first type being approximately 4 times greater than the second (Fig. 6).

Besides the predominantly Al-based studies on metals and alloy systems (due to malleable properties of the materials system, as discussed before), Jin et al. [60]

5 extended in situ TEM nanoindentation studies of ultrafine-grained materials to Fe thin films. Another iron-based system in the form of $0.4 \mathrm{wt} \%$ carbon-doped iron-tempered martensitic steel has also been studied through in situ nanoindentation tests in TEM [61], leading to the identification of dislocation-interface interactions and two types of boundaries in these dislocated structures. The electrical steel iron-based alloy system ${ }_{10}(3 \% \mathrm{Si}$ in $\mathrm{Fe})$ was studied in the form of single crystal thin films to determine the onset of plastic deformations to establish mechanical durability [62].

In addition to these three examples of in situ nanoindentation experiments on Febased alloys for commercial applications, Withey et al. [63] utilized this technique on gum metal - a complex alloy of $\mathrm{Ti}, \mathrm{Nb}, \mathrm{V}, \mathrm{Ta}, \mathrm{Zr}$, and $\mathrm{Hf}$. The experiments revealed 15 highly localized deformation occurring only in the vicinity of the indent, without creating any propagating defects, unique to this material. The real-time electron microscopy established that the deformed regions were highly inhomogeneous.

\subsubsection{In situ TEM nanoindentation of silicon nanocrystals and alloys}

20 In the early stages of developing quantitative TEM-based nanoindentation techniques, Minor et al. [64] reported direct observations of deformation mechanisms during the indentation in silicon through in situ TEM nanoindentation. This in situ technique has been applied to silicon nanoparticles to characterize their mechanical behavior [65]. The interactions between $50 \mathrm{~nm}$ Si nanoparticle clusters was studied in 
real-time, with the rotation of nanoparticles observed through changes in Bragg diffraction contrast of the micrographs (Fig. 7).

In situ TEM nanoindentation has been applied to metal silicides to determine chemical and crystallographic configurations which result in stable compositions. These 5 investigations are motivated by the need to understand common metal-silicon reactions, which hinder high temperature processes [66,67], and for applications of silicides as local interconnect materials in nanoelectronic devices [68,69]. Huitink et al. [70] observed interactions at the interface of $\mathrm{Au}$ and $\mathrm{Si}$ under the application of pressure. This work enabled the understanding of evolution of the crystal structure of gold silicide 10 under pressure [70] rather than temperature, and resulted in a non-equilibrium $\mathrm{AuSi}_{3}$ compound.

\subsubsection{Composite systems and pathways to improved analysis}

The prominent developments with in situ TEM nanoindentation have focused on

15 metal-based bulk and thin film materials systems. A few examples of applications of in situ nanoindentation with alternative materials systems are described below.

Evolution of viscoelastic-plastic deformation and crack growth of polymers was studied by qualitative in situ TEM nanoindentation [71]. In this work, specimens of ultrahigh molecular weight polyethylene (UHMWPE) were prepared by focused ion 20 beam (FIB) milling. Correlation of load-displacement characteristics with images of deformation processes is particularly valuable in polymeric systems where the degree of cross-linking and microstructure profoundly affect mechanical behavior [72]. The indentation-induced plasticity during loading and significant recovery of the deformed polymer upon unloading, and the initiation and development of fracture from a pre- 
existing surface nanodefect due to nanoindentation in the vicinity of fracture in the polymer specimens were observed during this study.

In situ TEM nanoindentation has also been utilized to study ceramic nanocomposites and oxide-glass thin films in two recent studies $[73,74]$. The first of

5 these studied the grain evolution and grain boundary displacements in alumina-zirconiamagnesia (AZM) spinel ceramic nanocomposites under indentation [73]. The latter work investigated the deformation behavior of $\mathrm{YBa}_{2} \mathrm{Cu}_{3} \mathrm{O}_{7-\mathrm{x}}(\mathrm{YBCO})$ thin films with twinning structures from both parallel and perpendicular directions to the twin surfaces [74].

While expanding the scope of materials systems to which in situ TEM nanoindentation is applied, significant research is required to develop full confidence in the quantified characterization of the nanomechanical processes and in theoretical understanding and interpretation of observations. Towards improved quantification, Nafari et al. [75] have reported the development of a capacitive force sensor for in situ

15 TEM nanoindentation with the capability of simultaneous force and current measurements.

Carlton et al. [76] observed the disappearance of dislocations in single-crystal silver nanoparticles after nanoindentation during real-time experimental observations. The ex situ load-displacement curves shed no light on post-indentation instabilities, and 20 disappearance of dislocations was observed only by in situ imaging. Based on these results, a new model for dislocation instability in nanomaterials was reported in relation to the change in Gibbs free energy of an edge dislocation [76-78]. There is significant scope for the development of similar models to explain real-time observations during nanoindentation which do not conform to the standard Oliver-Pharr [26] model. 


\section{HIGH TEMPERATURE NANOINDENTATION}

Elevated-temperature nanoindentation provides an additional capability to 5 nanoindentation techniques in the studies of fundamental materials physics. Such experiments are enticing to understand crystallization effects driven by both temperature and pressure, and their interplay. However, there are a number of technical issues such as temperature drift, sample oxidation, and heat management which limit the utilization of this in situ approach [79]. Despite these challenges, significant progress has been

10 made in experimental nanoindentation tests at elevated temperatures, with solutions to overcome or circumvent the perceived limitations.

Previous review articles on high temperature nanoindentation include those by Schuh et al. [80] and by Duan and Hodge [79]. In their review, Schuh et al. [80] highlight the timeline of publications and instruments used until 2005 and discuss in

15 detail the technical issues associated with this technique such as system calibration, instrumental and temperature drifts, and accuracy of quantitative properties extracted. Duan and Hodge [79] report on the advancements in high temperature nanoindentation in the decade since it was first introduced. It discusses some of the main equipment available, testing protocols, and refers to some of the properties which have been 20 studied by this technique such as incipient plasticity, glass transition temperatures, and phase transformations.

On the basis of two effective reviews outlining technology developments, the following section presents the applications of high temperature nanoindentation for different categories of materials systems, with the aim of guiding readers into evaluating 
the versatile benefits of this technique in materials characterization. A typical in situ high-temperature nanoindentation setup is presented in Fig. 8, with this arrangement varied based on the specific requirements of the study and for different nanoindentation systems.

5

\subsection{Metals and alloys}

Elevated temperature nanoindentation of metals and alloys has been of primary interest, in exploring their crystallization properties and phase stability. According to Schuh et al. [80], one of the first studies with high temperature indentation was by 10 Suzuki and Ohmura [81] using a custom built apparatus to study silicon at temperatures up to $600{ }^{\circ} \mathrm{C}$. This study highlighted the complexities and lack of stability of high temperature nanoindentation experiments.

Lund et al. [82] reported on the development of instrumentation for in situ high temperature nanoindentation tests. In this study, a heating stage monitored and

15 controlled by a thermocouple was introduced into the nanoindentation system allowing conductive heating of specimen up to the temperature of $200{ }^{\circ} \mathrm{C}$, while shielding the displacement transducer from the heat. Such shielding of the displacement transducer, possibly by cooling techniques (as in Fig. 8), has proved to be the most significant aspect for improving stability of high temperature nanoindentation experiments. For 20 indentation, in the work by Lund et al. [82], at each temperature the indenter tip was kept in contact with the sample for a period of time to attain thermal equilibrium. The instrumentation was then utilized to study the onset of plastic deformation in pure platinum single crystals, focusing on the effect of temperature. This research team also employed high temperature nanoindentation to quantitatively investigate dislocation 
nucleation in platinum [83]. In this work, indentation of platinum at elevated temperatures (up to $200{ }^{\circ} \mathrm{C}$ ) was accompanied by statistical analysis to investigate the first displacement burst in $P-h$ curves (Fig. 9). In similar work, a resistance heating stage was used in conjunction with a nanoindenter to study $\mathrm{Au}$ and $\mathrm{Cu}$ thin films on 5 silicon substrates at temperatures up to $130{ }^{\circ} \mathrm{C}$ [84]. It was shown that hardness and elastic modulus of these films decrease with increasing temperature.

Komvopoulos and Ma [85] have studied pseudo-elasticity behaviors of martensitic TiNi films via a set of in situ heating nanoindentation and in situ heating TEM studies (discussed earlier). TiNi samples heated through heating stage were 10 indented in temperatures up to $80^{\circ} \mathrm{C}$. To verify thermal stability of the force transducer, $\mathrm{SiC}$ films were also indented in the temperature range of $27-95^{\circ} \mathrm{C}$. In a related study, anomalous pseudo-elastic behavior was observed with martensitic TiNi films at an intermediate temperature of $55^{\circ} \mathrm{C}$, which was explained in terms of the increased twinned structure mobility [86].

Richter et al. [87] have studied mechanical properties of pure and intermetallic phases of Al-Ni-Si alloys at different temperatures using in situ hot stage nanoindentation. Their study provided a consolidated model of the temperaturedependent nanomechanical properties of this materials system by incorporating quantitative calculations, simulations, and ex situ AFM microscopy.

One of the first instances of higher temperature nanoindentation $\left(>200{ }^{\circ} \mathrm{C}\right.$ and up to $400{ }^{\circ} \mathrm{C}$ ) was reported by Sawant and Tin [88]. They performed high temperature nanoindentation tests on a single crystal Ni-based superalloy over a range of $30-400{ }^{\circ} \mathrm{C}$ and calculated the elastic modulus of the alloy as a function of temperature, incorporating creep compliance at peak load. During these experiments, precautions 
were taken to minimize sample oxidation, transient thermal fluctuations, and heat transfer during high temperature tests.

Alloys of Ni-W were studied by Trelewicz and Schuh [89] and the first set of observations on the activation parameters associated with the Hall-Petch breakdown

5 were reported. The temperature dependence of the deformation of these alloys (with 3 $80 \mathrm{~nm}$ grain sizes) over a range of $25-150{ }^{\circ} \mathrm{C}$ was studied.

High temperature nanoindentation has also been used to study the plastic flow behavior of $\mathrm{Ta}(001)$ in the temperature range of $25-200{ }^{\circ} \mathrm{C}[90]$. It was found that defect and dislocation nucleation in samples are strongly affected by the temperature.

10 The shape of $P-h$ curves is greatly altered with changes in temperature, accompanied by a strong decrease of the friction stress at higher temperatures. It was observed that the initial elastic loading sections are affected by the temperature and that the hardness decreases with the increase of temperature.

\section{4.2. Polymers}

Thermal analysis in the form of differential scanning calorimetry (DSC) is the technique for benchmarking polymer characteristics in the form of glass transition, crystallization, and melting temperatures. This makes high temperature nanoindentation a very relevant and complementary characterization technique. A novel modulated 20 indentation technique is presented by Sills et al. [91] and applied to thermal transition measurements of substrate-supported polymer thin films. In this technique, the capacitive load-displacement detector of the indenter acts as a sensor, extremely sensitive to thermally-induced changes in modulus of the sample, particularly at the glass transition. Measurements are conducted with indenter in contact with the sample 
under a constant applied load of 1-5 $\mu \mathrm{N}$ for each temperature step. A 15-60 s thermal equilibrium is allowed in each stage after which the amplitude and phase responses of the transducer signal (which correspond to load--displacement data) are recorded and averaged over a $15 \mathrm{~s}$ interval. This process is towards enhancing thermal stability of the 5 displacement measurements prior to and during the nanoindentation process. Glass transition studies of poly-t-butylacrylate were conducted and this technique proved accurate with the results comparing well with those from shear-modulated force microscopy and differential scanning calorimetry [91].

Gray and colleagues have also performed high temperature nanoindentation tests 10 on polyethylene films $[92,93]$. These experiments enabled the study of elevated temperature mechanical properties of poly films. The results allowed the correlation of the strain rate sensitivity parameter with $\tan (\delta)$ determined from conventional dynamic mechanical analysis (DMA). High values of the strain rate sensitivity parameter were observed only in the vicinity of the glass transition temperature. Lu et al. [94] have 15 performed nanoindentation tests at temperatures up to $200^{\circ} \mathrm{C}$ on PMR-15 polyimide neat resin using a heating stage. The experiments have been carried out in hold-at-peak mode using various holding times and unloading rates to enable measurement of normalized creep rate. Analytical procedures have been used to account for the effect of holding time and unloading rate on the calculations of contact depth, hardness and 20 elastic modulus. Recent in situ heating nanoindentation studies on polyamide 6 (PA6) revealed important information about the deformation mechanisms and high temperature behavior of this material and the correlation between nanoindentation and macro-tensile tests [95]. 


\subsection{Silica and bulk metallic glasses}

Fused silica was used in the development of nanoindentation with in situ heating as a reference material, due to its reputed temperature stability. Beake and Smith [96] studied differences in deformation behavior between fused silica and soda-lime glass.

5 This study found that the modulus of fused silica had stronger temperature dependence than what was previously observed and suggested caution should be exercised when using fused silica as a nanoindentation reference material at elevated temperatures.

In a subsequent study, Schuh et al. [80] have investigated technical issues surrounding high temperature nanoindentation and performed quantitative 10 measurements on specimens of standard fused silica at temperature up to $405^{\circ} \mathrm{C}$. In this comprehensive study, system equilibrium and steady-state condition for high temperature tests have been studied thoroughly, making note of thermal drifts at different temperatures. The hardness and Young's modulus of standard fused silica were studied over a temperature range of $23-405^{\circ} \mathrm{C}$, and these parameters are in quantitative 15 agreement with prior experimental literature.

This was the first time that high temperature nanoindentation data had been successfully validated against independent mechanical test data. To attain equilibrium during high temperature tests, the tip was brought into contact with the specimen at the test temperature, with extremely low load, following a heat redistribution period. After 20 contact, the tip was not to be retracted from the specimen for the duration of the test. The drift of the system after contact by the nanoindenter tip as a function of time is shown in Fig. 10. Since the thermal drift could not be entirely eliminated, a procedure was proposed to characterize the steady-state drift properties of the tip. It results in a master drift plot denoting drift range of the indenter tip at different temperatures [80]. 
In addition to fused silica, metal-based bulk glasses have also been characterized by high temperature nanoindentation. One of the first examples is the investigation of thermal activation in Au-based bulk metallic glasses through high temperature nanoindentation [97]. Indentations performed at temperatures up to $140{ }^{\circ} \mathrm{C}$ under a large 5 range of loads revealed transitions to homogenous states at temperature near the glass transition temperature, and enabled analysis of pop-in events and hardness measurements. Further experiments were undertaken by Li et al. [98] performed hightemperature nanoindentation on Au-based bulk metallic glass (containing $\mathrm{Au}, \mathrm{Ag}, \mathrm{Pd}$, $\mathrm{Cu}$, and $\mathrm{Si}$ ) with an in situ heating stage. Indentation size effect (ISE) was observed in 10 samples along with transition to homogeneous flow at elevated temperatures.

Deformation and ISE of the samples were shown to be dependent on the loading rate. High-temperature nanoindentation and in situ scanning probe microscopy were used to study the deformation of Pt-based glass [99]. Viscoelastic shape recovery was observed and measured in situ at various temperatures up to $250^{\circ} \mathrm{C}$.

\subsection{Silicon phase transformations}

Nanoindentation of silicon results in pressure-induced crystalline phases such as Si-III and Si-XII. Ruffell et al. [100] have used high temperature nanoindentation in their study of such phase transformations in silicon. It was observed that nucleation of

$20 \mathrm{Si}-\mathrm{III} / \mathrm{Si}$-XII is enhanced with increase in temperature. At sufficiently high temperatures, the Si-III/Si-XII nucleation occurs in amorphous silicon in a continuous fashion without a deformation event (Fig. 11). 


\section{IN SITU ELECTRICAL CHARACTERIZATION}

In the case of semiconductors, piezoelectrics, and other materials used in microelectromechanical systems (MEMS) and semiconductors industry, electrical properties and responses during stress and/or strain are of particular interest. Ex situ and

5 post-mortem characterization techniques cannot provide real-time insight into the deformation mechanisms of materials, and more importantly, they cannot be employed to evaluate the electrical response of the materials to the applied force, which is of particular interest. To this end, nanoindentation combined with in situ electrical characterization has proven to be a powerful tool. Moreover, it can also provide

10 additional detail during indentation experiments. For instance, Fang et al. [101] reported an in situ electrical characterization technique to continuously measure the contact area between the indenter and sample using the absolute area between $I-V$ curves continuously recorded during nanoindentation experiments.

In general, the electrical characterization during nanoindentation is performed 15 using a conductive nanoindenter tip and a current/voltage source. Various techniques have been developed allowing a time-based correlation between load-displacement and electrical characterization data [102]. Here, we report on different electrical characterization methods during nanoindentation tests and for applications as varied as nanoelectronics and energy harvesting.

\subsection{Semiconductor transformations and properties}

Silicon is the workhorse of the immense semiconductor industry, and its mechanical and electrical properties are of great interest. While the electrical and chemical properties of silicon are relatively well understood, its mechanical properties 
and dependence of electrical properties on mechanical stimuli are not well known, especially at the nanoscale. This has motivated extensive research in this area over the last decade and various in situ electrical characterization techniques have been developed to address the deformation mechanisms, phase transformations, and electrical 5 response of silicon (and other semiconductors) under an applied force. Other semiconductors which have been studied using this technique include germanium and gallium arsenide (GaAs).

Clarke et al. [103] reported on the nanoindentation-induced amorphization of single crystal silicon and germanium. The current was monitored as a function of the 10 applied voltage during indentation and behavioral changes from Schottky (diode-like) through to ohmic (resistor-like) and reversal to Schottky was studied during loading and unloading. Pharr et al. [104] investigated phase transformations in silicon and germanium by studying the electrical resistance of metal contacts on these substrates during nanoindentation. It was indicated that changes in resistance observed were due to 15 the interface of the metal to semiconductor rather contributions from the bulk semiconductor.

Bradby et al. [105] introduced a quantifiable and highly sensitive in situ electrical characterization technique to investigate the deformation behavior and phase transformations of crystalline silicon during nanoindentation. In this study, a silicon 20 epilayer was probed during nanoindentation, allowing the measurement of the current through a reverse-biased Schottky diode formed by the configuration which would turn to an ohmic contact following the formation of a pressure-induced metallic $\mathrm{Si}$-II phase under the indenter (Fig. 12). As this configuration was particularly sensitive to the Si-I to $\mathrm{Si}-\mathrm{II}$ phase transformation, it proved useful in detecting such changes and correlating 
them with load-displacement data acquired from nanoindentation tests. Further, phase transformations to either low pressure Si-III/Si-XII or amorphous-Si phases were identified from the current measurements during unloading, with the formation or nucleation of such phases depending on the unloading rate.

$5 \quad$ Given the sensitivity of this in situ electrical nanoindentation technique in detecting silicon phase transformations, the same group developed methods for in situ electrical measurements using a doped diamond indenter tip. The doped diamond tips utilize the hardness to diamond to expand the range of materials that electrical nanoindentation can be applied to. This was utilized to further investigate phase 10 transformations of crystalline silicon under high pressure [106,107]. In Ruffell et al. [106], information from post-indent $I-V$ curves and previous TEM and Raman spectroscopy measurements were correlated with the electrical behavior and phase transformations during nano indentation. Measurements of current flowing through the nanoindenter tip and sample during an indentation cycle was carried out (associated 15 with load/unload curve), with a constant voltage applied [107]. This allows the system to be extremely sensitive to conductivity changes in the material below the indenter tip and also allows voltage monitoring throughout the loading and unloading cycle (Fig. 13). A further development to this technique was reported by Fujisawa et al. [108] which consisted of combining cyclic loading with electrical measurements to monitor 20 phase transformations during unloading. Changes in mechanical behavior and electrical conductivity were monitored and the phase transformation changes were verified using TEM data.

Another novel approach to investigate the evolution of metastable Si-II metallic phase of crystalline Si during nanoindentation with a high spatial resolution employed 
in situ scanning spreading resistance microscopy (SSRM). In this work [109], a diamond AFM probe was used for nanoindentation while a direct current (DC) bias was applied between a back contact on the back surface of the sample and AFM tip to realize a stable electrical contact. The resulting current was measured using a 5 logarithmic current amplifier enabling the monitoring of electrical conductivity $v s$. applied force, and the detection of phase transformation by detecting a fall in resistivity. The experimental results were correlated with molecular dynamics simulation which predicted a new metastable phase of silicon Si-XIII when using a larger indenter tip. The relationship between indenter tip size, contact area, and phase transformations in 10 silicon are also discussed [109].

An in situ electrical contact resistance measurement was introduced to monitor delamination of conductor-semiconductor specimens [110]. Measurements were carried out in quasi-static and oscillating loading modes on TiN thin films on steel. A pop-in event together with a current drop was identified as the detection signal for 15 delamination occurring in both loading regimes.

In a nanoindentation study on GaAs, Nowak et al. [111] employed in situ electrical probing to simultaneously record mechanical and electrical response of an uncoated sample during the experiment. This study examined the pop-in events previously reported for GaAs, which were indicated by discontinuities in the load20 displacement curves. During the experiments, an electrical current spike was generated in direct relation to the mechanical pop-in event in the load-displacement curve. This sharp increase in current suggested the occurrence of a pressure-induced phase transformation in GaAs, in contrast with previous assumptions about the onset of plasticity in GaAs. 


\subsection{Piezoelectric properties and energy harvesting}

The need to characterize the electromechanical properties of piezoelectric and ferroelectric materials has served as a driving force in developing nanoscale probing 5 techniques that combine mechanical stimuli with electrical measurements, and vice versa. Nanoindentation has been used to characterize both piezoelectric bulk materials and thin films, with the early in situ electrical experiments relying on significant modification of instrumentation.

The initial studies provided a theoretical background for employing indentation 10 techniques with electrical measurements for the characterization of piezoelectric materials $[112,113]$. Sridhar et al. [113] also carried out experimental characterization with in situ electrical measurements to study mechanical and electrical responses of piezoelectric bulk materials (commercial lead zirconate titanate PZT-4 and barium titanate $\mathrm{BaTiO}_{3}$ ). This study was performed using a conductive and electrically 15 grounded spherical indenter tip, with an electrometer connected between the indenter and ground to measure the quasi-static current induced in the sample. It was found that increasing indentation velocity (loading rate) increased the current magnitude and switching the poling direction in the films under study reversed the polarity of the measured current. Indentation velocities up to $50 \mu \mathrm{m} \mathrm{min}^{-1}$ and a maximum load of $20300 \mathrm{~N}$ were used. Similar experiments were carried out using a conical indenter tip by the same group which showed that after a certain load, inelastic deformation sets in and analytical predictions based on linear models no longer apply [114].

Algueró et al. [115] studied stress-induced depolarization in lanthanum-modified lead titanate thin films. The nanoindenter tip was used as the top electrode to pole the 
thin films by applying a field of $150 \mathrm{kV} \mathrm{cm}^{-1}$. The depolarization current density under indentation was measured, and correlated with the movements of $90^{\circ}$ domain walls. In another study by the same group, this force induced domain wall motion and ferroelectric switching was investigated further, this time for calcium-modified lead 5 titanate thin films [116]. Ferroelectric hysteresis loops under indentation force were obtained using a tungsten carbide and cobalt (WC-Co) spherical indenter, also acting as an electrode to enable electrical measurements. Under applied mechanical force and voltage, the resulting current density and electric charge were evaluated using Hertzian theory. Their study revealed that mechanical stress prevents the ferroelectric hysteresis 10 loops from becoming saturated. This hinders the ferroelectric switching process and results in large coercive fields (up to $400 \mathrm{kV} \mathrm{cm}^{-1}$ ).

Koval et al. [117] investigated the electromechanical response of pure and Mndoped PZT films of 700 and $70 \mathrm{~nm}$ thicknesses during nanoindentation. Stress-induced electrical current transients were measured in situ via the use of an electrometer under a 15 mechanical load applied by a spherical indenter. The conductive indenter tip was used as the top electrode while a Pt layer served as the bottom electrode as shown in Fig. 14. Under the nanoindentation load, an electrical current which is the aggregate of intrinsic response and force-dependent extrinsic contribution of domain walls was measured. Their results showed a non-linear behavior in the electromechanical response of the thin 20 films within the sub-coercive stress range.

A new approach for quantitative characterization of piezoelectric materials, referred to as piezoelectric nanoindentation (PNI), was reported with the use of an oscillating voltage applied across the sample under study [118]. In PNI, utilizing the oscillating voltage applied between the indenter and sample in a standard 
nanoindentation system with continuous stiffness measurement, the first harmonic of bias-induced surface area at the contact area is detected. Lead zirconate titanate (PZT) and barium titanate $\left(\mathrm{BaTiO}_{3}\right)$ ceramics were examined, and their piezoelectric constants were measured under the converse piezoelectric effect (applying a voltage and 5 measuring resulting strain-induced displacement). These results provided a quantitative insight into the electromechanical response of piezoelectrics.

Drawing on the developments reported by Koval et al. [117] and Rar et al. [118], quantitative measurement of the longitudinal piezoelectric coefficient of strontiumdoped PZT (PSZT) thin films were carried out by Sriram et al. [119] by combining the 10 accuracy of the nanoindenter for displacement measurement and the converse piezoelectric effect. The change in the thickness of thin films was monitored while applying an electric potential across the thickness of the film. Utilizing the mapping capabilities of the nanoindenter, the piezoelectric response of the thin films has been studied over large areas to determine uniformity and possible correlation with 15 microstructure $[119,120]$. This enabled the determination of the average piezoelectric response of the material, along with identifying maxima and minima.

The piezoelectric response characterization was extended to the direct piezoelectric effect using a commercial in situ electrical nanoindentation instrument (Hysitron Triboindenter with NanoECR). In this work, controlled forces were applied to 20 piezoelectric thin films and electron beam lithography defined piezoelectric nanoislands, as shown in Figs. 15a and 15b [121]. These materials were tested with varying levels of force and loading rates to determine the open circuit voltage and short circuit current generation during nanoindentation (Fig. 15c). Measurements were done using impulse, sustained, and staircase forces to investigate the response under the 
direct piezoelectric effect, with typical measurement results shown in Figs. 15d and 15e. The programmable mapping capabilities of the nanoindenter again enabled the study of uniformity of voltage generation for different levels of force Fig. 15f. Voltages of up to $40 \mathrm{mV}$ and current transients of $200 \mathrm{pA}$ were measured under a load of $5 \mathrm{mN}$, with

5 estimated direct piezoelectric response coefficient in agreement with those measured under the converse effect. This study demonstrated the nanoscale electromechanical scientific insight that can be gained from in situ electrical nanoindentation, and provided quantitative characterization of the energy generation capabilities of piezoelectric materials at the nanoscale.

\section{COMBINED IN SITU APPROACHES}

The majority of this review presents nanoindentation with either in situ visualization or measurement. More recently, the various approaches and developments 15 have been combined to maximize the scientific insight gained from the nanoscale characterization processes. The following section describes combined in situ nanoindentation approaches applied to two very topical materials systems - graphene and lead-free ferroelectrics.

\section{6.1. Strain-dependent graphene bandgaps}

Graphene is a two-dimensional gapless semiconductor with outstanding mechanical properties. It is capable of withstanding very high mechanical strains that are most likely to change its bandgap structure resulting in electrical-mechanical coupling in graphene. Therefore, the electrical characterization of graphene under such 
mechanical forces is of particular interest. Huang et al. [46] have reported a combination of two in situ nanoindentation approaches - electrical and SEM - to study the nanoelectromechanical response of graphene to moderate strains. Constant load hold was incorporated to allow $I-V$ electrical measurements for each strain level. Further, by 5 taking a highly-doped silicon substrate as the back gate, the band structure of graphene under strain was studied through measuring its electronic transport and the conductance was recorded as a function of gate voltage for different strains (Fig. 16).

The nanoindentation-dependent gate voltage measurements by Huang et al. [46] also combined in situ SEM imaging of the graphene ribbon-like devices. The experiments were carried out inside a custom-made instrument (SEMentor) composed of a field-emission gun SEM and a nanomechanical module similar to a nanoindenter. Figure 17 shows the experimental arrangement and a series of images taken during the indentation of a graphene ribbon. The mechanical deformation is shown to be elastic with $100 \%$ reversibility of the stiffness-displacement data.

\subsection{Field-induced transformations in piezoelectrics}

Similar to the combined SEM and electrical in situ nanoindentation measurements on graphene described above, Zhang et al. [122] studied the electric field-induced strains during nanoindentation in lead-free piezoelectric $\mathrm{BiFeO}_{3}(\mathrm{BFO})$ thin films inside

20 a TEM. BFO is considered an attractive alternative to lead-based piezoelectrics with large electromechanical constants.

In this work [122], electrical fields were applied during nanoindentation of the samples with a conductive AFM tip to acquire piezoelectric hysteresis loops. Further, BFO thin films were electrically probed directly at the nanoscale and were imaged using 
TEM. A $20 \mathrm{~V}$ voltage was applied to the specimen through the TEM nanoindenter module to observe the reversible motion of phase boundary. The results obtained (Fig. 18) provided evidence of field-induced phase transformations in the BFO thin films, explaining the origin of the $>5 \%$ field-induced strain observed in BFO thin films.

5 This finding reinforces the potential use of BFO thin films in piezoelectric applications.

\section{CONCLUSIONS AND OUTLOOK}

Utilizing nanoindentation in combination with electron microscopy and thermal or 10 electrical stimuli has provided an understanding of mechanical, crystalline, and conductive modifications in materials, especially in the form of thin films and nanostructures. This nanoscale probing has also highlighted deficiencies of existing understanding of materials systems and inadequacies of accepted theoretical models for their behavior. As shown by Fig. 19, significant recent progress has been attained in 15 combining in situ nanoindentation techniques to study multifunctional properties. While preparing and presenting a review on the advances of in situ nanoindentation and its contributions to the progress in materials science had it challenges given the disparate pieces of literature, we have endeavored to present a combination of prevalent techniques with immense potential categorizing their utilization on the basis of 20 materials systems.

The information provided by in situ nanoindentation increasingly reinforces the ability of this technique to help us understand nanoscale properties of materials, especially multifunctional behavior. The value of the results from in situ nanoindentation has resulted in more specific areas of investigation. One such 
development is quantitative high temperature nanoindentation, with increased operating temperature range. This recent advancement reports on nanoindentation tests at temperatures up to $500{ }^{\circ} \mathrm{C}$ [123]. This system was designed to operate in inert atmospheres, including vacuum as well as Ar and He gas environments, and utilized 5 active cooling of transducers.

In situ nanoindentation can be effectively utilized to address grand challenges in materials science across all disciplines. Soft matter including organic, polymeric, and biological systems can benefit from visualizing rupture of cell walls under direct and shear forces, cell death under pressure while monitoring electrochemical variations, and 10 mapping of cellular potential at the nanoscale. Nanoscale probing has been effectively combined to track surface changes from electrochemical processes [124-128]. The recent use of nanoindentation under electrical stimuli [122] and measurement of piezoelectric energy generation under pressure [121] have opened up new opportunities to study nanoscale electromechanics. Combining these studies with the high resolution 15 mapping capabilities to commercial nanoindentation systems will enable correlation of electromechanical properties with nanostructural morphology, crystallography, and stoichiometry. This specifically applies to research into quasi-two-dimensional materials, such as graphene and structurally similar transition metal oxides and sulfides $[129,130]$, where mapping of electrical and electronic properties at the nanoscale is 20 critical to understanding fundamental carrier transport processes.

In summary, in situ nanoindentation has matured significantly from early experiments and diversified into new areas with advances in technology. Rather than just focusing on imaging during nanoindentation, the effect of external stimuli is also being increasingly studied. These guarantee that in situ nanoindentation will 
increasingly become a tool of choice in materials research of thin films and nanostructures. The results will prove valuable in complementing spectroscopy, microscopy, and diffraction analyses in providing a full portrayal of multifunctionality at the nanoscale.

\section{ACKNOWLEDGEMENTS}

The authors thank colleagues and collaborators who have contributed to aspects of research reported in this work. Research support and fellowships from the Australian

10 Research Council through Discovery Projects (DP1092717 and DP110100262) and infrastructure funding (LE110100223) are acknowledged.

\section{REFERENCES}

15 1. De Hosson JTM. Advances in transmission electron microscopy: In situ straining and in situ compression experiments on metallic glasses. Microsc Res Tech 2009;72:250-60.

2. Hohmann-Marriott MF, Sousa AA, Azari AA, Glushakova S, Zhang G, Zimmerberg J, et al. Nanoscale 3D cellular imaging by axial scanning transmission electron tomography. Nat Meth 2009;6:729-31.

3. Morgan AB, Gilman JW. Characterization of polymer-layered silicate (clay) nanocomposites by transmission electron microscopy and X-ray diffraction: A comparative study. J Appl Polym Sci 2003;87:1329-38. 
4. Muller DA. Structure and bonding at the atomic scale by scanning transmission electron microscopy. Nat Mater 2009;8:263-70.

5. Schroder DK. Nano Characterization of Materials. ECS Transactions 2010;33:322.

5 6. Varela M, Lupini AR, Benthem Kv, Borisevich AY, Chisholm MF, Shibata N, et al. Materials characterization in the aberration-corrected scanning transmission electron microscope. Annual Review of Materials Research 2005;35:539-69.

7. Loos J. The Art of SPM: Scanning Probe Microscopy in Materials Science. Adv Mater 2005;17:1821-33.

10 8. Park JY, Maier S, Hendriksen B, Salmeron M. Sensing current and forces with SPM. Mater Today 2010;13:38-45.

9. Garleff JK, Wijnheijmer AP, Koenraad PM. Challenges in cross-sectional scanning tunneling microscopy on semiconductors. Semicond Sci Technol 2011;26:064001.

15 10. Tourek CJ, Sundararajan S. Atom Scale Characterization of the Near Apex Region of an Atomic Force Microscope Tip. Microsc Microanal 2010;16:636-42.

11. Bombis C, Kalashnyk N, Xu W, Lægsgaard E, Besenbacher F, Linderoth TR. Hydrogen-Bonded Molecular Networks of Melamine and Cyanuric Acid on Thin Films of $\mathrm{NaCl}$ on $\mathrm{Au}(111)$. Small 2009;5:2177-82.

20 12. Lee J, Choi I, Hong S, Lee S, Yang YI, Kim Y, et al. Construction of pcAFM module to measure photoconductance with a nanoscale spatial resolution. Ultramicroscopy 2008;108:1090-3. 
13. Reid OG, Munechika K, Ginger DS. Space charge limited current measurements on conjugated polymer films using conductive atomic force microscopy. Nano Lett 2008;8:1602-9.

14. Xu D, Watt GD, Harb JN, Davis RC. Electrical conductivity of ferritin proteins by conductive AFM. Nano Lett 2005;5:571-7.

15. Seemann L, Stemmer A, Naujoks N. Local surface charges direct the deposition of carbon nanotubes and fullerenes into nanoscale patterns. Nano Lett 2007;7:3007-12.

16. Bogan MJ, Benner WH, Boutet S, Rohner U, Frank M, Barty A, et al. Single Particle X-ray Diffractive Imaging. Nano Lett 2007;8:310-6.

17. de Smit E, Swart I, Creemer JF, Hoveling GH, Gilles MK, Tyliszczak T, et al. Nanoscale chemical imaging of a working catalyst by scanning transmission Xray microscopy. Nature 2008;456:222-5.

18. Larson BC, Yang W, Ice GE, Budai JD, Tischler JZ. Three-dimensional X-ray structural microscopy with submicrometre resolution. Nature 2002;415:887-90.

19. Robinson I, Harder R. Coherent X-ray diffraction imaging of strain at the nanoscale. Nat Mater 2009;8:291-8.

20. Sakdinawat A, Attwood D. Nanoscale X-ray imaging. Nat Photon 2010;4:840-8.

21. Li X, Chasiotis I, Kitamura T. In Situ Scanning Probe Microscopy Nanomechanical Testing. MRS Bull 2010;35:361-7.

22. Oliver WC, Pharr GM. Nanoindentation in materials research: Past, present, and future. MRS Bull 2010;35:897-907.

23. Marks LD, Warren OL, Minor AM, Merkle AP. Tribology in Full View. MRS Bull 2008;33:1168-73. 
24. Robertson IM, Schuh CA, Vetrano JS, Browning ND, Field DP, Jensen DJ, et al. Towards an integrated materials characterization toolbox. J Mater Res 2011;26:1341-83.

25. Schuh CA. Nanoindentation studies of materials. Mater Today 2006;9:32-40.

5 26. Oliver WC, Pharr GM. Improved technique for determining hardness and elastic modulus using load and displacement sensing indentation experiments. J Mater Res 1992;7:1564-80.

27. Wall MA, Dahmen U. Development on an in situ nanoindentation specimen holder for the high voltage electron microscope. Microsc Microanal 1997;3:593-4.

10 28. Wall MA, Dahmen U. An in situ nanoindentation specimen holder for a high voltage transmission electron microscope. Microsc Res Tech 1998;42:248-54.

29. Berkovich ES. Three-Faceted Diamond Pyramid for Studying Microhardness by Indentation. Zavodskaya Laboratoria 1950;13:345-7.

30. Khrushchov MM, Berkovich ES. Methods of Determining the Hardness of Very Hard Materials: The Hardness of Diamond. Ind Diamond Rev 1951;11:42-9.

31. Sprouster DJ, Ruffell S, Bradby JE, Williams JS, Lockrey MN, Phillips MR, et al. Structural characterization of B-doped diamond nanoindentation tips. J Mater Res 2011;26:3051-7.

32. Legros M, Gianola DS, Motz C. Quantitative in situ mechanical testing in electron microscopes. MRS Bull 2010;35:354-60.

33. Carlton CE, Ferreira PJ. In situ TEM nanoindentation of nanoparticles. Micron 2012. doi: 10.1016/j.micron.2012.03.002

34. Nowak JD, Rzepiejewska-Malyska KA, Major RC, Warren OL, Michler J. In-situ nanoindentation in the SEM. Mater Today 2010;12:44-5. 
35. Rabe R, Breguet JM, Schwaller P, Stauss S, Haug FJ, Patscheider J, et al. Observation of fracture and plastic deformation during indentation and scratching inside the scanning electron microscope. Thin Solid Films 2004;469-470:206-13.

36. Moser B, Kuebler J, Meinhard H, Muster W, Michler J. Observation of Instabilities during Plastic Deformation by in-situ SEM Indentation Experiments. Adv Eng Mater 2005;7:388-92.

37. Moser B, Löffler JF, Michler J. Discrete deformation in amorphous metals: an in situ SEM indentation study. Philos Mag 2006;86:5715-28.

38. Rzepiejewska-Malyska KA, Buerki G, Michler J, Major RC, Cyrankowski E, Asif SAS, et al. In situ mechanical observations during nanoindentation inside a highresolution scanning electron microscope. J Mater Res 2008;23:1973-9.

39. Rzepiejewska-Malyska KA, Parlinska-Wojtan M, Wasmer K, Hejduk K, Michler J. In-situ SEM indentation studies of the deformation mechanisms in TiN, CrN and TiN/CrN. Micron 2009;40:22-7.

15 40. Rzepiejewska-Malyska KA, Mook WM, Parlinska-Wojtan M, Hejduk J, Michler J. In situ scanning electron microscopy indentation studies on multilayer nitride films: Methodology and deformation mechanisms. J Mater Res 2009;24:1208-21.

41. Ghisleni R, Rzepiejewska-Malyska K, Philippe L, Schwaller P, Michler J. In situ SEM indentation experiments: Instruments, methodology, and applications. Microsc Res Tech 2009;72:242-9.

42. Vecchione N, Wasmer K, Balint DS, Nikbin K. Characterization of EB-PVD yttrium-stabilised zirconia by nanoindentation. Surf Coat Technol 2009;203:17437. 
43. Deuschle JK, Buerki G, Deuschle HM, Enders S, Michler J, Arzt E. In situ indentation testing of elastomers. Acta Mater 2008;56:4390-401.

44. Khodasevych IE, Shah CM, Sriram S, Bhaskaran M, Withayachumnankul W, Ung BSY, et al. Elastomeric silicone substrates for terahertz fishnet metamaterials.

5 Appl Phys Lett 2012;100:061101.

45. Narimissa E, Gupta R, Bhaskaran M, Sriram S. Influence of nano-graphite platelet concentration on onset of crystalline degradation in polylactide composites. Polym Degrad Stab 2012;97:829-32.

46. Huang M, Pascal TA, Kim H, Goddard WA, Greer JR. Electronic-Mechanical Coupling in Graphene from in situ Nanoindentation Experiments and Multiscale Atomistic Simulations. Nano Lett 2011;11:1241-6.

47. Maschmann MR, Zhang Q, Wheeler R, Du F, Dai L, Baur J. In situ SEM Observation of Column-like and Foam-like CNT Array Nanoindentation. ACS Appl Mater Interfaces 2011;3:648-53.

15 48. Stach EA, Freeman T, Minor AM, Owen DK, Cumings J, Wall MA, et al. Development of a Nanoindenter for In Situ Transmission Electron Microscopy. Microsc Microanal 2001;7:507-17.

49. Bobji MS, Pethica JB, Inkson BJ. Indentation mechanics of $\mathrm{Cu}-\mathrm{Be}$ quantified by an in situ transmission electron microscopy mechanical probe. J Mater Res $2005 ; 20: 2726-32$.

50. Bobji MS, Ramanujan CS, Doole RC, Pethica JB, Inkson BJ. An in-situ TEM nanoindenter system with 3-axis inertial positioner. MRS Proc 2003;778:U4.5.16. 
51. Minor A, Lilleodden E, Stach E, Morris J. In-situ transmission electron microscopy study of the nanoindentation behavior of Al. J Electron Mater 2002;31:958-64.

52. Minor AM, Lilleodden ET, Stach EA, Morris JW. Direct observations of incipient $5 \quad$ plasticity during nanoindentation of Al. J Mater Res 2004;19:176-82.

53. Minor A, Stach E, Morris J, Petrov I. In-situ nanoindentation of epitaxial TiN/MgO (001) in a transmission electron microscope. J Electron Mater 2003;32:1023-7.

54. Minor AM, Syed Asif SA, Shan Z, Stach EA, Cyrankowski E, Wyrobek TJ, et al. A new view of the onset of plasticity during the nanoindentation of aluminium. Nat Mater 2006;5:697-702.

55. Kiener D, Minor AM. Source truncation and exhaustion: Insights from quantitative in situ TEM tensile testing. Nano Lett 2011;11:3816-20.

56. Jin M, Minor AM, Stach EA, Morris JJW. Direct observation of deformationinduced grain growth during the nanoindentation of ultrafine-grained $\mathrm{Al}$ at room temperature. Acta Mater 2004;52:5381-7.

57. Soer WA, Hosson JTMD, Minor AM, Morris Jr JW, Stach EA. Effects of solute $\mathrm{Mg}$ on grain boundary and dislocation dynamics during nanoindentation of $\mathrm{Al}-\mathrm{Mg}$ thin films. Acta Mater 2004;52:5783-90.

20 58. De Hosson J, Soer W, Minor A, Shan Z, Stach E, Syed Asif S, et al. In situ TEM nanoindentation and dislocation-grain boundary interactions: a tribute to David Brandon. J Mater Sci 2006;41:7704-19. 
59. Li N, Wang J, Huang JY, Misra A, Zhang X. In situ TEM observations of room temperature dislocation climb at interfaces in nanolayered $\mathrm{Al} / \mathrm{Nb}$ composites. Scripta Mater 2010;63:363-6.

60. Jin M, Minor AM, Ge D, Morris JW. Study of Deformation Behavior of Ultrafine5 grained Materials Through in Situ Nanoindentation in a Transmission Electron Microscope. J Mater Res 2005;20:1735-40.

61. Ohmura T, Minor AM, Stach EA, Morris JW. Dislocation-grain boundary interactions in martensitic steel observed through in situ nanoindentation in a transmission electron microscope. J Mater Res 2004;19:3626-32.

10 62. Zhang L, Ohmura T, Seikido K, Nakajima K, Hara T, Tsuzaki K. Direct observation of plastic deformation in iron-3\% silicon single crystal by in situ nanoindentation in transmission electron microscopy. Scripta Mater 2011;64:91922.

63. Withey E, Jin M, Minor A, Kuramoto S, Chrzan DC, Morris Jr JW. The deformation of "Gum Metal" in nanoindentation. Mater Sci Eng, A 2008;493:2632.

64. Minor AM, Lilleodden ET, Jin M, Stach EA, Chrzan DC, Morris JW. Room temperature dislocation plasticity in silicon. Philos Mag 2005;85:323-30.

65. Lockwood AJ, Inkson BJ. In situ TEM nanoindentation and deformation of Sinanoparticle clusters. J Phys D: Appl Phys 2009;42:035410.

66. Sriram S, Bhaskaran M, Mitchell DRG, Short KT, Holland AS, Mitchell A. Microstructural and Compositional Analysis of Strontium-Doped Lead Zirconate Titanate Thin Films on Gold-Coated Silicon Substrates. Microsc Microanal $2009 ; 15: 30-5$. 
67. Sriram S, Bhaskaran M, Kostovski G, Mitchell DRG, Stoddart PR, Austin MW, et al. Synthesis of Self-Assembled Island-Structured Complex Oxide Dielectric Films. J Phys Chem C 2009;113:16610-4.

68. Bhaskaran M, Sriram S, Holland AS. Interfacial Resistive Properties of Nickel Silicide Thin Films to Doped Silicon. J Electrochem Soc 2010;157:H842-6.

69. Bhaskaran M, Sriram S, Short KT, Mitchell DRG, Holland AS, Reeves GK. Characterization of C54 titanium silicide thin films by spectroscopy, microscopy and diffraction. J Phys D: Appl Phys 2007;40:5213-9.

70. Huitink D, Peng L, Ribeiro R, Liang H. In situ observation of stress-induced AuSi phase transformation. Appl Phys Lett 2009;94:183111.

71. Zhou J, Komvopoulos K, Minor AM. Nanoscale plastic deformation and fracture of polymers studied by in situ nanoindentation in a transmission electron microscope. Appl Phys Lett 2006;88:181908.

72. Pruitt LA. Deformation, yielding, fracture and fatigue behavior of conventional and highly cross-linked ultra high molecular weight polyethylene. Biomat 2005;26:905-15.

73. Lee JH, Kim I, Hulbert DM, Jiang D, Mukherjee AK, Zhang X, et al. Grain and grain boundary activities observed in alumina-zirconia-magnesia spinel nanocomposites by in situ nanoindentation using transmission electron microscopy. Acta Mater 2010;58:4891-9.

74. Lee JH, Zhang X, Wang H. Direct observation of twin deformation in $\mathrm{YBa}_{2} \mathrm{Cu}_{3} \mathrm{O}_{7-\mathrm{x}}$ thin films by in situ nanoindentation in TEM. J Appl Phys 2011;109:083510. 
75. Nafari A, Angenete J, Svensson K, Sanz-Velasco A, Enoksson P. MEMS sensor for in situ TEM-nanoindentation with simultaneous force and current measurements. J Micromech Microeng 2010;20:064017.

76. Carlton CE, Lourie O, Ferreira PJ. In-situ TEM nano-indentation of individual $5 \quad$ single-crystal nanoparticles. Microsc Microanal 2007;13:576-7.

77. Carlton CE, Ferreira PJ. Dislocation motion-induced strain in nanocrystalline materials: Overlooked considerations. Mater Sci Eng, A 2008;486:672-4.

78. Carlton CE, Rabenberg L, Ferreira PJ. On the nucleation of partial dislocations in nanoparticles. Philos Mag Lett 2008;88:715-24.

10 79. Duan Z, Hodge A. High-temperature nanoindentation: New developments and ongoing challenges. JOM J Miner Metals Mater Soc 2009;61:32-6.

80. Schuh CA, Packard CE, Lund AC. Nanoindentation and contact-mode imaging at high temperatures. J Mater Res 2006;21:725-36.

81. Suzuki T, Ohmura T. Ultra-microindentation of silicon at elevated temperatures. Philos Mag A 1996;A74:1073-84.

82. Lund AC, Hodge AM, Schuh CA. Incipient plasticity during nanoindentation at elevated temperatures. Appl Phys Lett 2004;85:1362-4.

83. Schuh CA, Mason JK, Lund AC. Quantitative insight into dislocation nucleation from high-temperature nanoindentation experiments. Nat Mater 2005;4:617-21.

20 84. Volinsky AA, Moody NR, Gerberich WW. Nanoindentation of Au and Pt/Cu thin films at elevated temperatures. J Mater Res 2004;19:2650-7.

85. Komvopoulos K, Ma XG. Pseudoelasticity of martensitic titanium-nickel shapememory films studied by in situ heating nanoindentation and transmission electron microscopy. Appl Phys Lett 2005;87:263108. 
86. Ma X-G, Komvopoulos K. In situ transmission electron microscopy and nanoindentation studies of phase transformation and pseudoelasticity of shapememory titanium-nickel films. J Mater Res 2005;20:1808-13.

87. Richter A, Chen CL, Smith R, McGee E, Thomson RC, Kenny SD. Hot stage nanoindentation in multi-component Al-Ni-Si alloys: Experiment and simulation. Mater Sci Eng, A 2008;494:367-79.

88. Sawant A, Tin S. High temperature nanoindentation of a Re-bearing single crystal Ni-base superalloy. Scripta Mater 2008;58:275-8.

89. Trelewicz JR, Schuh CA. Hot nanoindentation of nanocrystalline Ni-W alloys. Scripta Mater 2009;61:1056-9.

90. Rajulapati KV, Biener MM, Biener J, Hodge AM. Temperature dependence of the plastic flow behavior of tantalum. Philos Mag Lett 2009;90:35-42.

91. Sills S, Fong H, Buenviaje C, Sarikaya M, Overney RM. Thermal transition measurements of polymer thin films by modulated nanoindentation. J Appl Phys 2005;98:014302.

92. Gray A, Beake BD. Elevated Temperature Nanoindentation and Viscoelastic Behaviour of Thin Poly(ethylene terephthalate) Films. J Nanosci Nanotechnol $2007 ; 7: 2530-3$

93. Gray A, Orecchia D, Beake BD. Nanoindentation of Advanced Polymers Under Non-Ambient Conditions: Creep Modelling and Tan Delta. J Nanosci Nanotechnol 2009;9:4514-9.

94. Lu Y, Jones D, Tandon G, Putthanarat S, Schoeppner G. High Temperature Nanoindentation of PMR-15 Polyimide. Exp Mech 2010;50:491-9. 
95. Seltzer R, Kim J-K, Mai Y-W. Elevated temperature nanoindentation behaviour of polyamide 6. Polym Int 2011;60:1753-61.

96. Beake BD, Smith JF. High-temperature nanoindentation testing of fused silica and other materials. Philos Mag A 2002;82:2179-86.

5 97. Yang B, Wadsworth J, Nieh T-G. Thermal activation in Au-based bulk metallic glass characterized by high-temperature nanoindentation. Appl Phys Lett 2007;90:061911.

98. Li N, Liu L, Chan KC, Chen Q, Pan J. Deformation behavior and indentation size effect of Au49Ag5.5Pd2.3Cu26.9Si16.3 bulk metallic glass at elevated temperatures. Intermetallics 2009;17:227-30.

99. Packard CE, Schroers J, Schuh CA. In situ measurements of surface tensiondriven shape recovery in a metallic glass. Scripta Mater 2009;60:1145-8.

100. Ruffell S, Bradby JE, SWilliams J, Munoz-Paniagua D, Tadayyon S, Coatsworth LL, et al. Nanoindentation-induced phase transformations in silicon at elevated temperatures. Nanotechnol 2009;20:135603.

101. Fang L, Muhlstein CL, Collins JG, Romasco AL, Friedman LH. Continuous electrical in situ contact area measurement during instrumented indentation. $\mathrm{J}$ Mater Res 2008;23:2480-5.

102. Nowak J, Major R, Oh J, Shan Z, Asif S, Warren O. Developments in In Situ Nanomechanical Testing. Microsc Microanal 2010;16:462-3.

103. Clarke DR, Kroll MC, Kirchner PD, Cook RF, Hockey BJ. Amorphization and Conductivity of Silicon and Germanium Induced by Indentation. Phys Rev Lett $1988 ; 60: 2156-9$ 
104. Pharr GM, Oliver WC, Cook RF, Kirchner PD, Kroll MC, Dinger TR, et al. Electrical resistance of metallic contacts on silicon and germanium during indentation. J Mater Res 1992;7:961-72.

105. Bradby JE, Williams JS, Swain MV. In situ electrical characterization of phase transformations in Si during indentation. Phys Rev B 2003;67:085205.

106. Ruffell S, Bradby JE, Fujisawa N, Williams JS. Identification of nanoindentationinduced phase changes in silicon by in situ electrical characterization. J Appl Phys 2007;101:083531.

107. Ruffell S, Bradby JE, Williams JS, Warren OL. An in situ electrical measurement technique via a conducting diamond tip for nanoindentation in silicon. J Mater Res 2007;22:578-86.

108. Fujisawa N, Ruffell S, Bradby JE, Williams JS, Haberl B, Warren OL. Understanding pressure-induced phase-transformation behavior in silicon through in situ electrical probing under cyclic loading conditions. J Appl Phys 2009;105:106111.

109. Mylvaganam K, Zhang LC, Eyben P, Mody J, Vandervorst W. Evolution of metastable phases in silicon during nanoindentation: mechanism analysis and experimental verification. Nanotechnol 2009;20:305705.

110. Nguyen HH, Wei PJ, Lin JF. Electric contact resistance for monitoring nanoindentation-induced delamination. Adv Nat Sci: Nanosci Nanotechnol 2011;2:015007.

111. Nowak R, Chrobak D, Nagao S, Vodnick D, Berg M, Tukiainen A, et al. An electric current spike linked to nanoscale plasticity. Nat Nanotechnol 2009;4:28791. 
112. Giannakopoulos AE, Suresh S. Theory of indentation of piezoelectric materials. Acta Mater 1999;47:2153-64.

113. Sridhar S, Giannakopoulos AE, Suresh S, Ramamurty U. Electrical response during indentation of piezoelectric materials: A new method for material characterization. J Appl Phys 1999;85:380-7.

114. Sridhar S, Giannakopoulos AE, Suresh S. Mechanical and electrical responses of piezoelectric solids to conical indentation. J Appl Phys 2000;87:8451-6.

115. Algueró M, Bushby AJ, Reece MJ, Poyato R, Ricote J, Calzada ML, et al. Stressinduced depolarization of $(\mathrm{Pb}, \mathrm{La}) \mathrm{TiO}_{3}$ ferroelectric thin films by nanoindentation. Appl Phys Lett 2001;79:3830-2.

116. Algueró M, Calzada ML, Bushby AJ, Reece MJ. Ferroelectric hysteresis loops of $(\mathrm{Pb}, \mathrm{Ca}) \mathrm{TiO}_{3}$ thin films under spherical indentation. Appl Phys Lett 2004;85:20235.

117. Koval V, Reece MJ, Bushby AJ. Ferroelectric/ferroelastic behavior and piezoelectric response of lead zirconate titanate thin films under nanoindentation. J Appl Phys 2005;97:074301.

118. Rar A, Pharr GM, Oliver WC, Karapetian E, Kalinin SV. Piezoelectric nanoindentation. J Mater Res 2006;21:552-6.

119. Sriram S, Bhaskaran M, Holland AS, Short KT, Latella BA. Measurement of high piezoelectric response of strontium-doped lead zirconate titanate thin films using a nanoindenter. J Appl Phys 2007;101:104910.

120. Sriram S, Bhaskaran M, Mitchell A. Low-temperature deposition of high-response piezoelectric thin films. Scripta Mater 2010;63:189-91. 
121. Bhaskaran M, Sriram S, Ruffell S, Mitchell A. Nanoscale Characterization of Energy Generation from Piezoelectric Thin Films. Adv Funct Mater 2011;21:2251-7.

122. Zhang JX, Xiang B, He Q, Seidel J, Zeches RJ, Yu P, et al. Large field-induced strains in a lead-free piezoelectric material. Nat Nanotechnol 2011;6:98-102.

123. Trenkle JC, Packard CE, Schuh CA. Hot nanoindentation in inert environments. Rev Sci Instrum 2010;81:073901.

124. Barnoush A, Bies $\mathrm{C}$, Vehoff $\mathrm{H}$. In situ electrochemical nanoindentation of FeAl (100) single crystal: Hydrogen effect on dislocation nucleation. J Mater Res 2009;24:1105-13.

125. Barnoush A, Dake J, Kheradmand N, Vehoff H. Examination of hydrogen embrittlement in FeAl by means of in situ electrochemical micropillar compression and nanoindentation techniques. Intermetallics 2010;18:1385-9.

126. Barnoush A, Vehoff $\mathrm{H}$. Electrochemical nanoindentation: A new approach to probe hydrogen/deformation interaction. Scripta Mater 2006;55:195-8.

127. Barnoush A, Vehoff H. In situ electrochemical nanoindentation: A technique for local examination of hydrogen embrittlement. Corros Sci 2008;50:259-67.

128. Barnoush A, Vehoff H. Hydrogen embrittlement of aluminum in aqueous environments examined by in situ electrochemical nanoindentation. Scripta Mater 2008;58:747-50.

129. Balendhran S, Ou JZ, Bhaskaran M, Sriram S, Ippolito S, Vasic Z, et al. Atomically Thin Layers of $\mathrm{MoS}_{2}$ via a Two Step Thermal EvaporationExfoliation Method. Nanoscale 2012;4:461-6. 
130. Radisavljevic B, Radenovic A, Brivio J, Giacometti V, Kis A. Single-layer $\mathrm{MoS}_{2}$ transistors. Nat Nanotechnol 2011;6:147-50. 


\section{FIGURE CAPTIONS}

Figure 1. In situ SEM indentation results for a $1.5 \mu \mathrm{m} \mathrm{TiN} / \mathrm{SiN}_{\mathrm{x}}$ thin film on silicon. SEM micrographs from various points in the loading cycle are presented. Nanocrack 5 formation (indicated by circles) can be observed. (Figure reproduced from Ref. [35].)

Figure 2. CAD image of the Hysitron's SEM-based force-displacement transducer. The $x-y-z$ coordinate system is related to the transducer, which is tilted off-axis to allow SEM imaging of the sample surface during the indentation cycle. The transducer 10 components are: 1 . Lower part of the main frame; 2 . Supporting rib; 3 . Upper part of the main frame; 4. Transducer in its support; 5. Conductive indenter probe; 6. $z$ slip-stick actuator; 7. $x, y$ slip-stick actuators; 8. Removable sample holder; 9. SEM stage; 10. SEM electron gun; and 11. SEM high-magnification detector. (Figure reproduced from Ref. [38].)

Figure 3. In situ observation of a $7.5 \mu \mathrm{m}$ VACNT array at (a) $20 \%$ strain,

(b) postbuckling at $60 \%$ strain, (c) maximum compression of $90 \%$ strain, and (d) upon full retraction of indenter tip. The marked (blue) line indicates the approximate contour of a single CNT. (Figure reproduced from Ref. [47].)

Figure 4. Schematic of in situ TEM nanoindentation specimen holders. This figure from Stach et al. [48] shows an adapted version of the Wall and Dahmen [27,28] holder in (a) and the holder designed for JEOL TEMs in (b). 
Figure 5. In situ nanoindentation results for grains in an Al thin film. Micrographs of two grains: (a) reference image; (b) after nanoindentation showing same diffraction condition; and (c) overlaid micrograph showing significant grain boundary movement. (Figure reproduced from Ref. [52].)

5

Figure 6. Results from the in situ nanoindentation of $5 \mathrm{~nm}$ multilayers of $\mathrm{Al} / \mathrm{Nb}$ thin films. (a) Cross-sectional TEM micrograph of multilayer film under the nanoindentor tip. (b) High resolution TEM micrograph of marked region in (a) showing dislocations, with film interfaces indicated. (c) The evolution of dislocation densities both inside the 10 layers and at the interfaces with time during indentation. Stacking faults can be observed in the high resolution TEM micrograph in (d) and the corresponding processed image in (e). (Figure reproduced from Ref. [59].)

Figure 7. In situ nanoindentation of a cluster of silicon nanoparticles: (a) just prior to 15 contact with strong Bragg contrast visible; (b-d) time delayed micrographs at consecutive loading steps; (e) 0.04 s prior to fracture; and (f) fracture during the fourth loading step. (Figure reproduced from Ref. [65].)

Figure 8. Schematic of typical instrumentation for high temperature nanoindentation. 20 (Figure reproduced from Ref. [79].)

Figure 9. Statistics of the first displacement burst resulting from the nanoindentation of platinum. (a) Typical $P-h$ curves at three temperatures, and the initial part of the curve matches the expectations of Hertzian elastic contact theory (continuous lines). (b) The 
cumulative distribution of the load at the first displacement burst shown to have significant temperature dependence. (Figure reproduced from Ref. [83].)

Figure 10. Equilibration characteristics of the nanoindentation apparatus at various test 5 temperatures are presented. The instantaneous drift rate is plotted as a function of time from the moment of the first tip contact with the hot specimen. The reported values are the average of the pre-indentation and post-indentation ( $80 \%$ unload) measurements. The several data sets are vertically offset for clarity of presentation. (Figure reproduced from Ref. [80].)

Figure 11. Representative load/unload curves for temperature-dependent nanoindentation of crystalline (dotted) and amorphous (continuous) silicon. Curves for temperatures of $25,50,100$, and $125^{\circ} \mathrm{C}$ are shown (shifted to greater depth for clarity). At higher temperatures some pop-outs were observed to be less distinct and can be 15 described as kink-like. (Figure reproduced from Ref. [100].)

Figure 12. Schematic of experimental setup for in situ electrical nanoindentation of silicon. The silicon structure consists of an epilayer on low resistance silicon. Aluminum was evaporated onto both sides and a closed circuit for current measurement 20 was created. (Figure reproduced from Ref. [105].)

Figure 13. Current-voltage curves extracted during nanoindentation unloading highlighting sensitivity of in situ electrical nanoindentation in determining pressureinduced phase transformations. (Figure reproduced from Ref. [106].) 
Figure 14. Schematic drawing of in situ electrical nanoindentation setup used to study electromechanical response of piezoelectric thin films. (Figure reproduced from Ref. [117].)

5

Figure 15. In situ electrical nanoindentation to characterize energy generation from piezoelectric materials. Electron micrographs of thin films and nanoislands are shown in (a) and (b), respectively. Schematic of the electrical measurement arrangement is shown in (c). Typical results for (d) voltage generation, (e) current generation, and (f) mapping 10 voltage generation at different forces. (Figure adapted from Ref. [121].)

Figure 16. (a) Schematic representation of nanoindentation to induce mechanical strain in a graphene ribbon device. (b) Strain-dependent electrical characteristics of a graphene ribbon. (Figure reproduced from Ref. [46].)

Figure 17. In situ nanoindentation with electrical characterization and SEM imaging of a graphene ribbon device: (a) the experimental setup; (b) typical load-displacement and contact stiffness data; and (c-h) series of micrographs during nanoindentation experiments on a graphene ribbon with different stages identified in (b). (Figure 20 reproduced from Ref. [46].)

Figure 18. In situ electrical TEM nanoindentation. Bright-field TEM micrographs:

(a) before and (b) after the application of an electric field by the nanoindenter tip. Evolution of selected area electron diffraction patterns under probe voltages of (c) $0 \mathrm{~V}$, 
(d) $20 \mathrm{~V}$, and (e) back to $0 \mathrm{~V}$. Bright-field images and evolution of the diffraction patterns indicate the reversible phase transition between mixed and pure tetragonal phase under a probe-applied electric field. (Figure reproduced from Ref. [122].)

5 Figure 19. Illustrative depiction of in situ nanoindentation approaches, with the year of first reports for each category of techniques indicated. Recent progress in utilizing electron microscopy and combined in situ techniques can be utilized for many materials systems. 


\section{FIGURES}

\section{Figure 1}
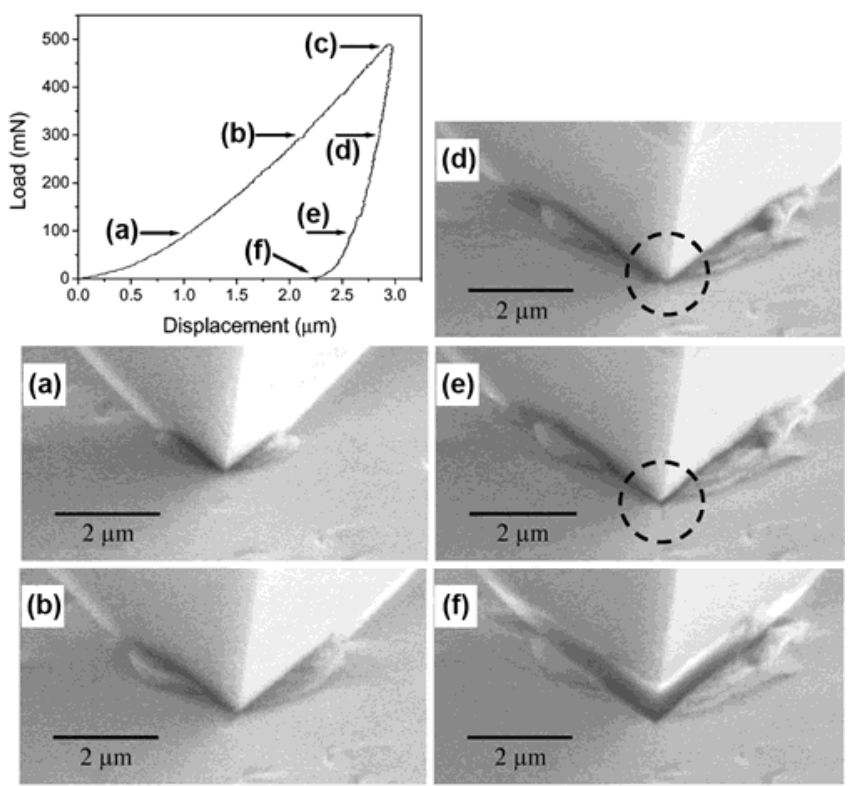

(c)

(g)

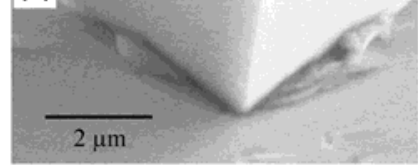

$2 \mu \mathrm{m}$

5 


\section{Figure 2}

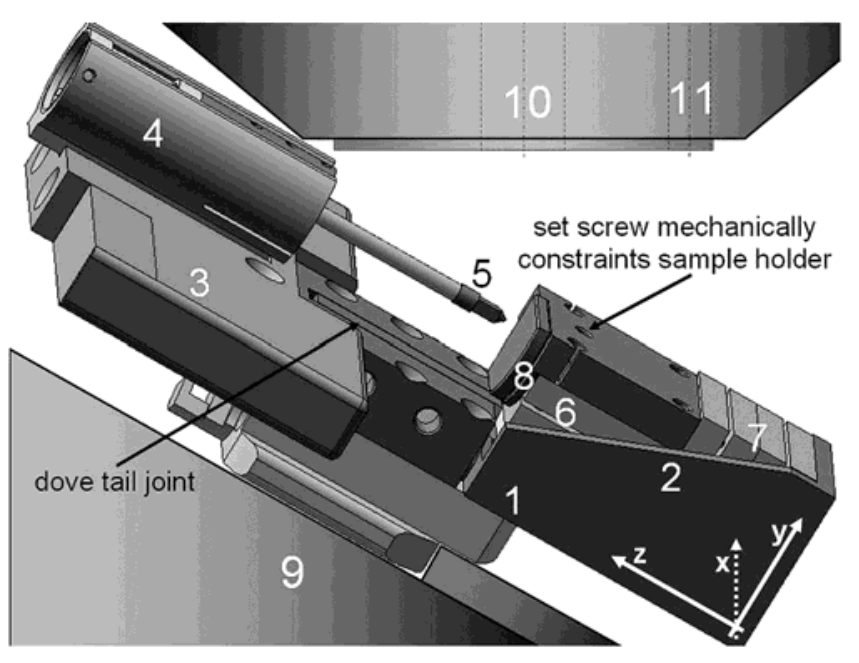




\section{Figure 3}

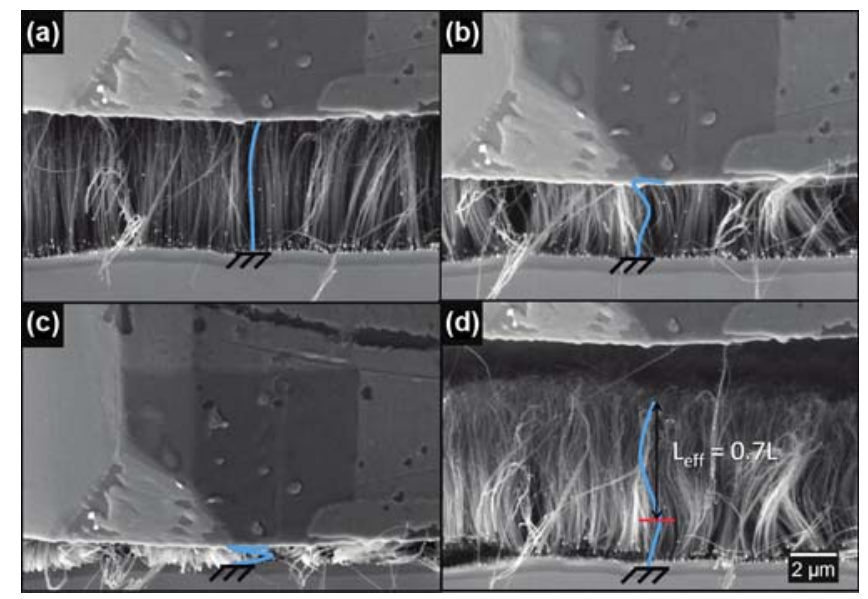


Submitted for Peer-Review to Progress in Materials Science

\section{Figure 4}

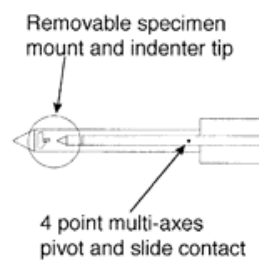

(a)

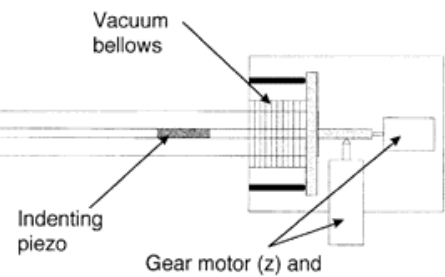

screw piezo (x\&y) drives

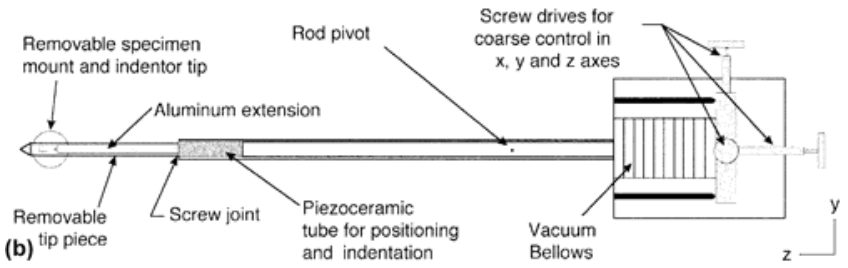




\section{Figure 5}

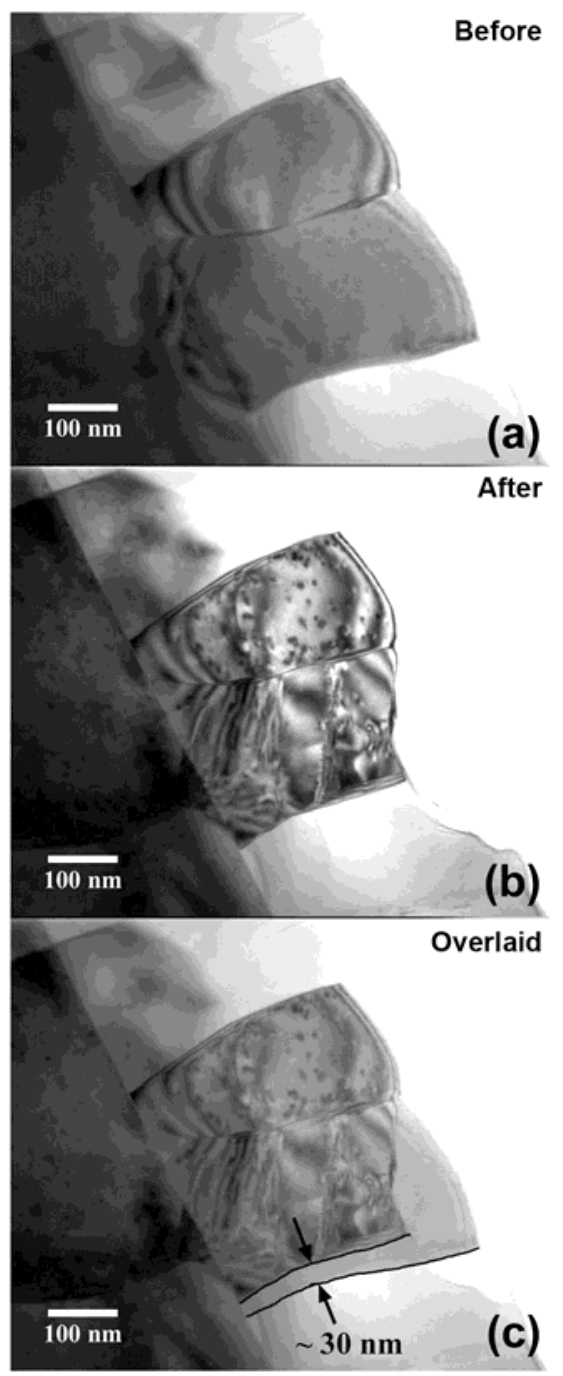


Figure 6
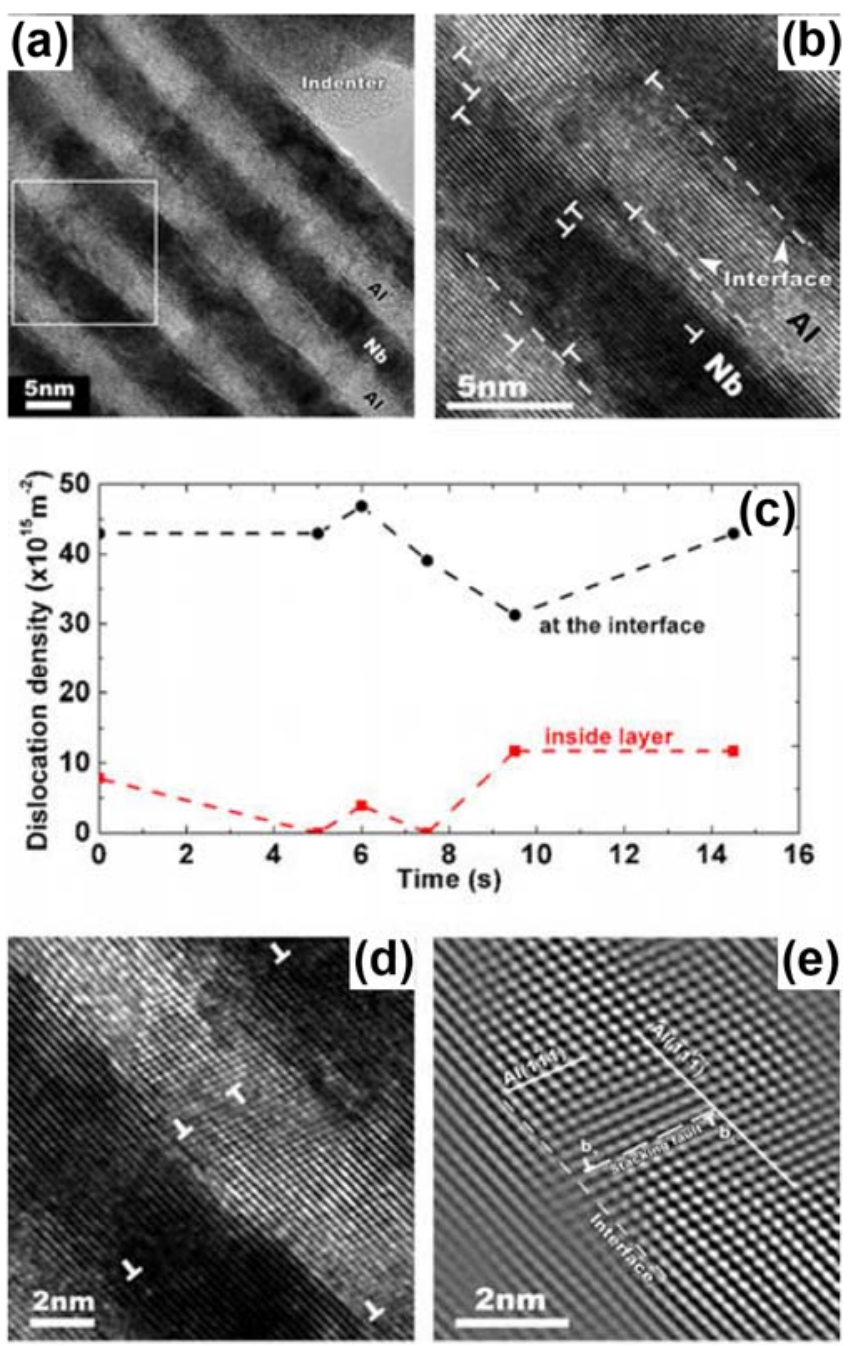

(e) 
Figure 7

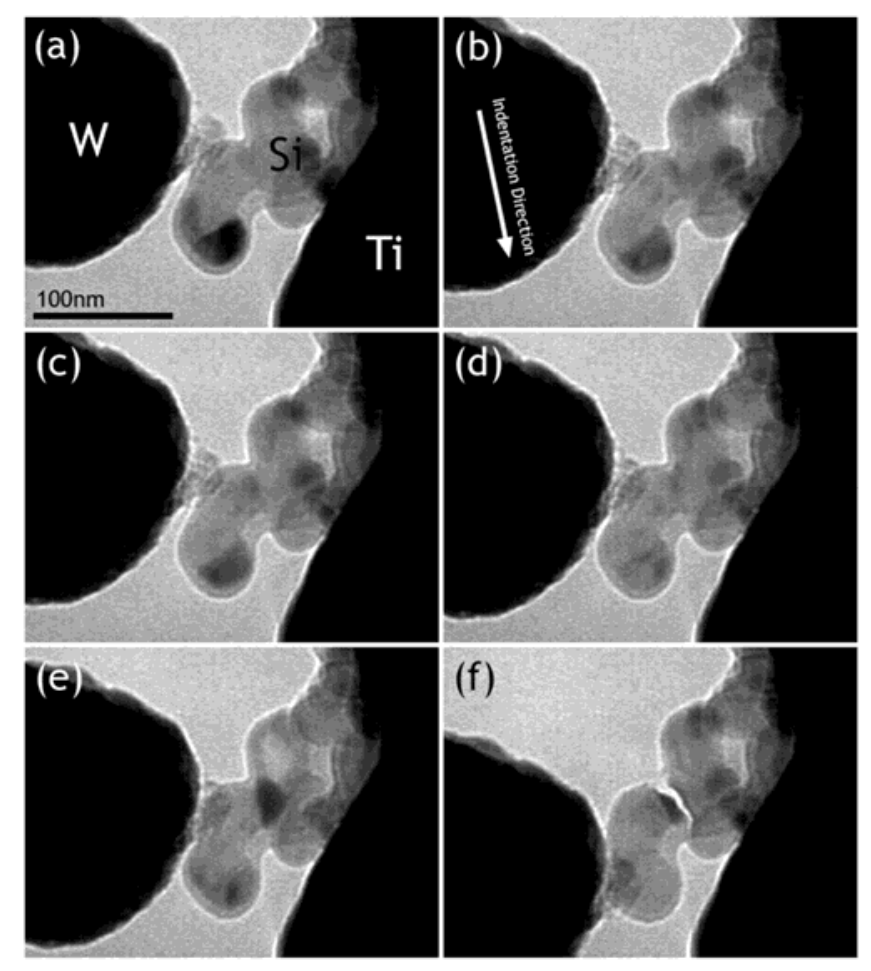


Submitted for Peer-Review to Progress in Materials Science

\section{Figure 8}

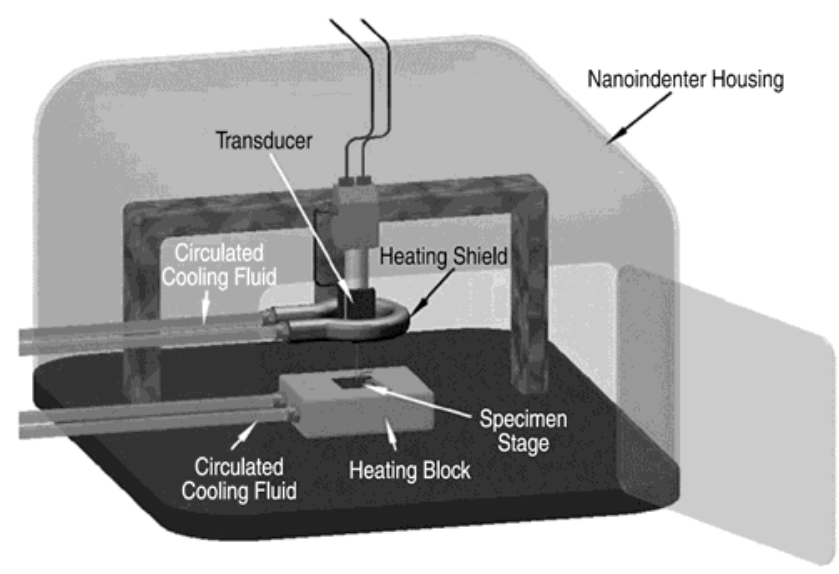




\section{Figure 9}
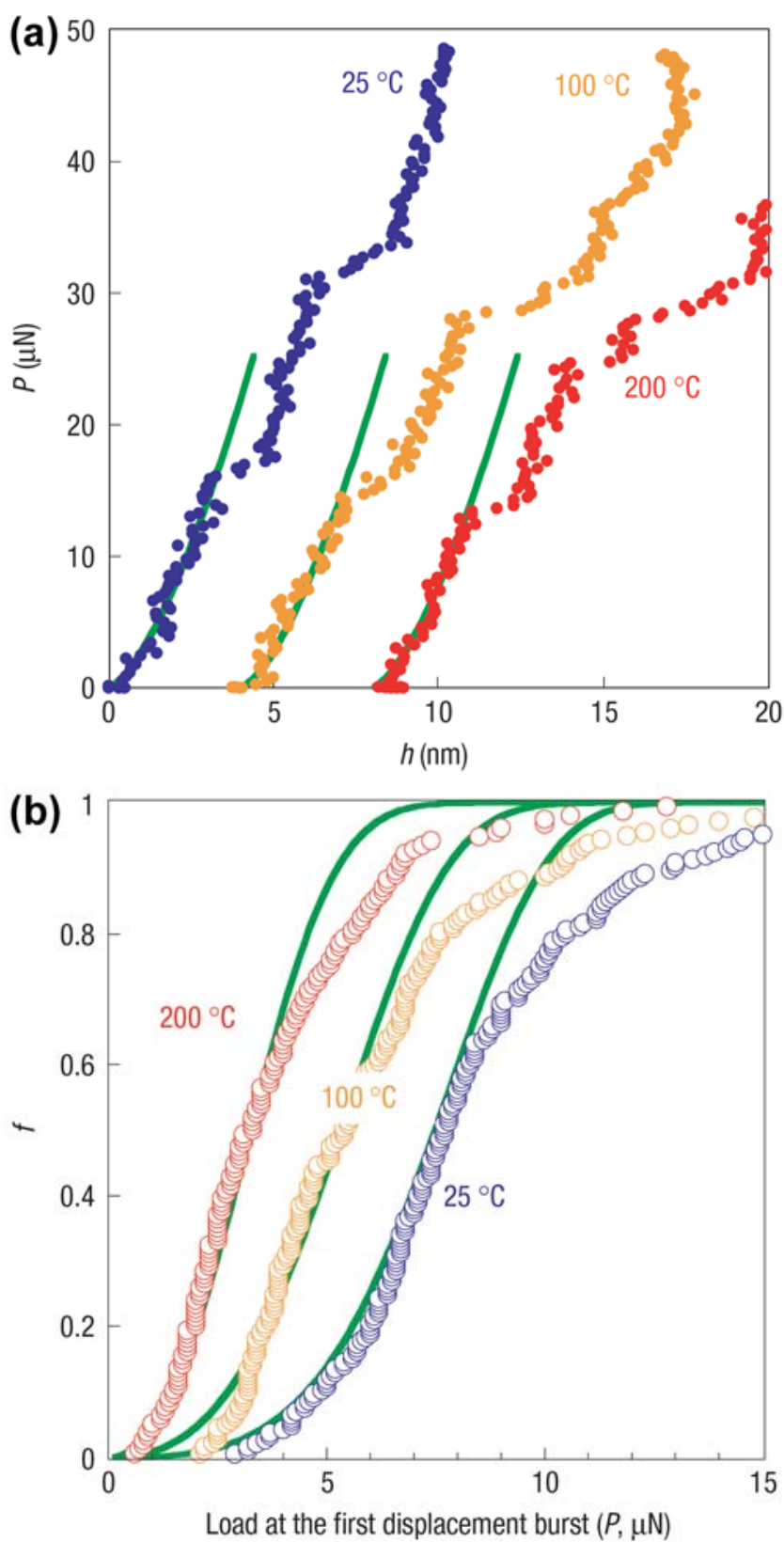


\section{Figure 10}

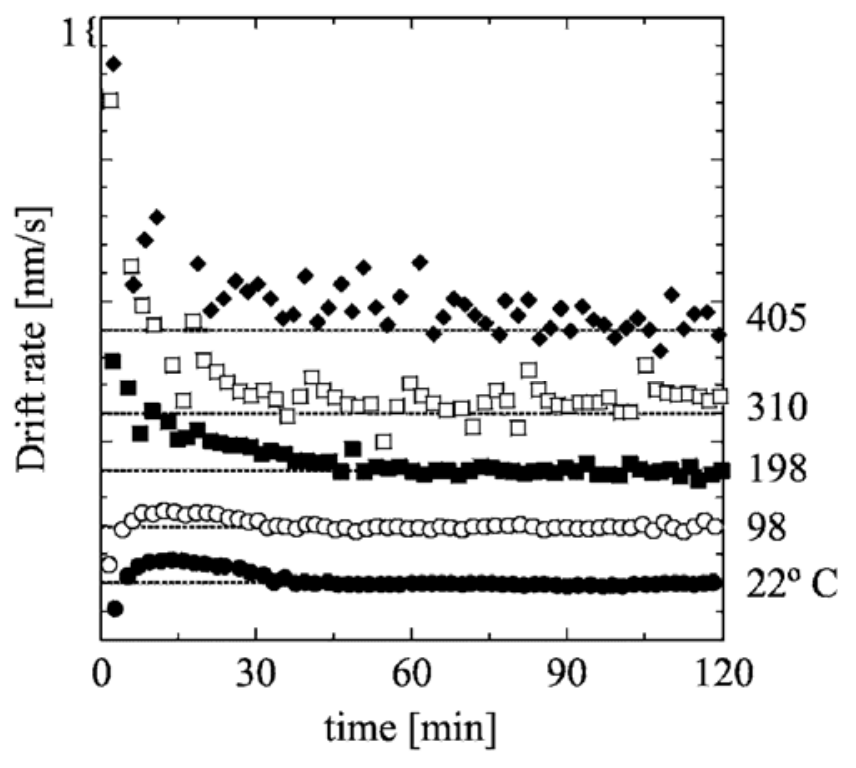




\section{Figure 11}

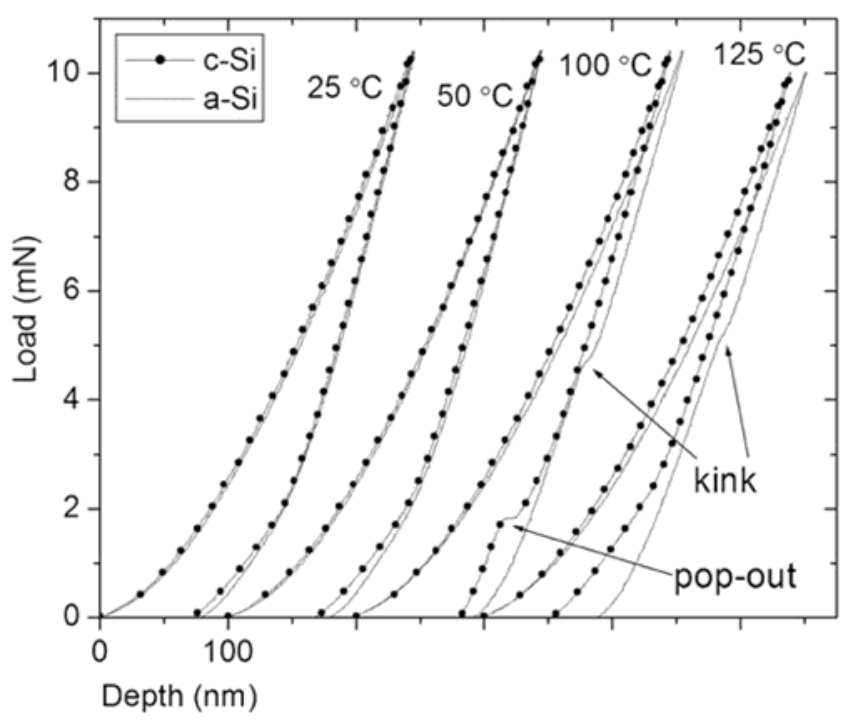


Figure 12

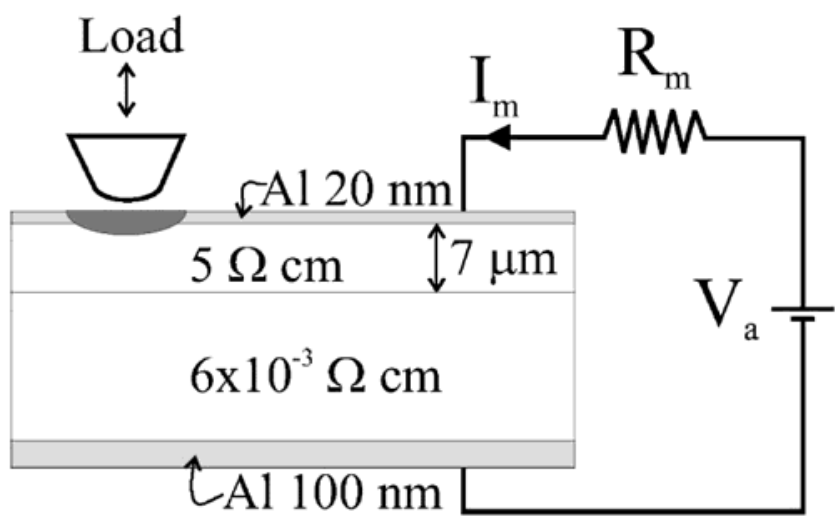




\section{Figure 13}

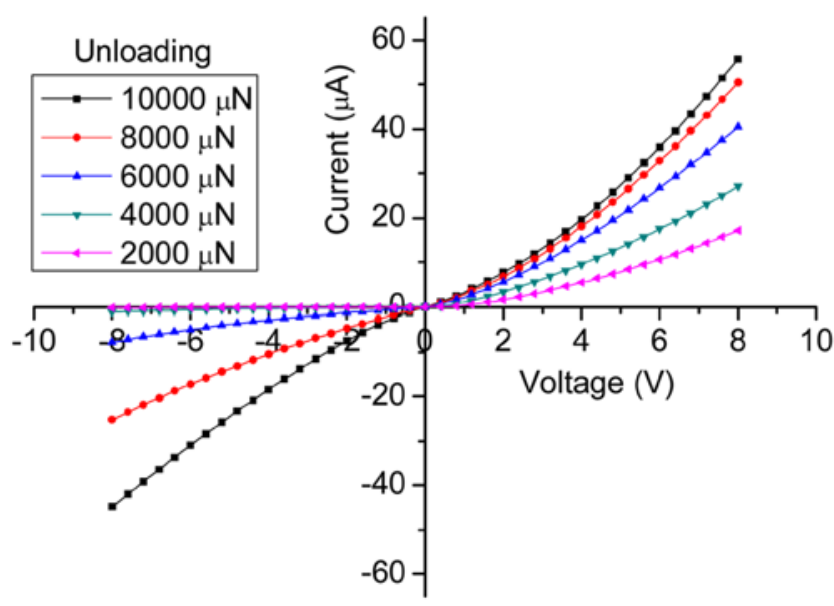




\section{Figure 14}

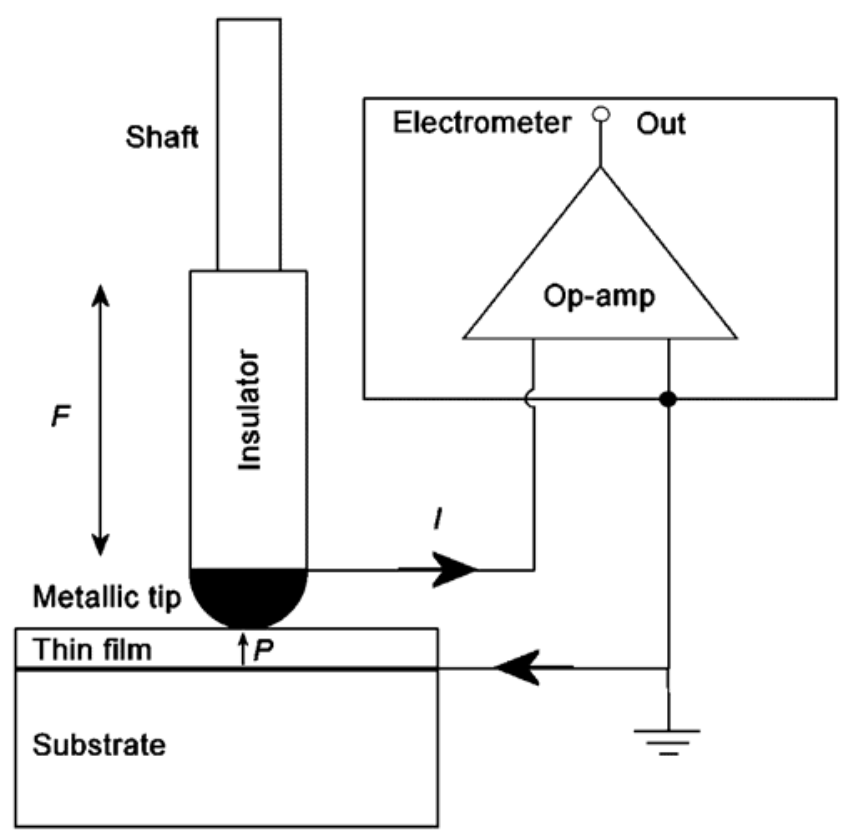




\section{Figure 15}

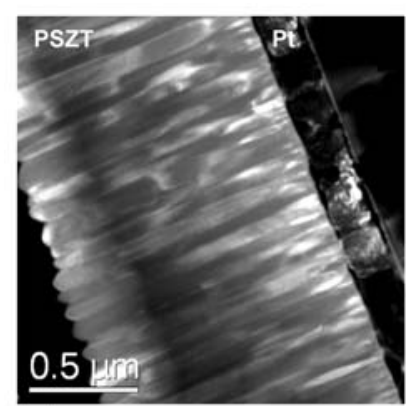

(a)

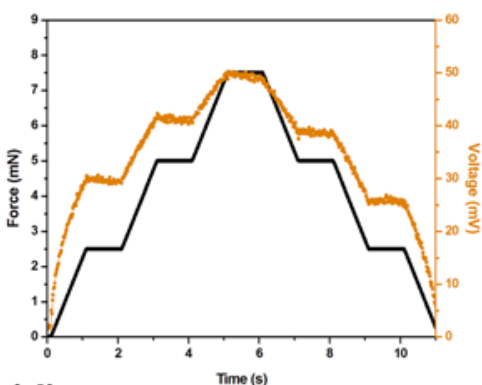

(d)

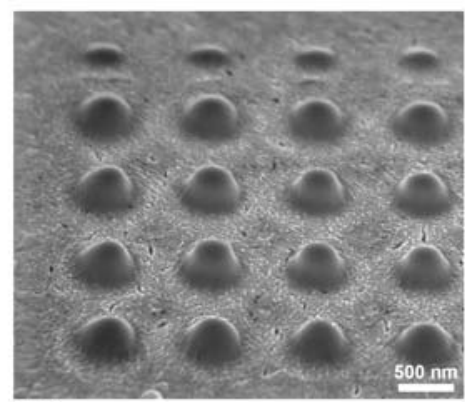

(b)

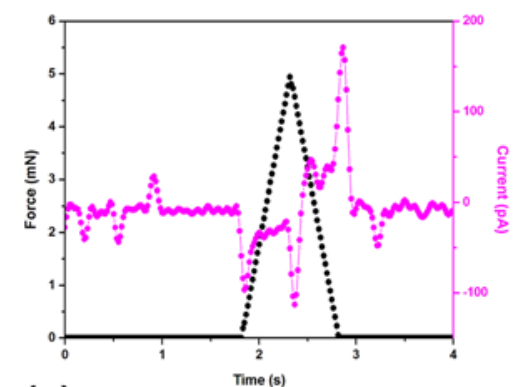

(e)

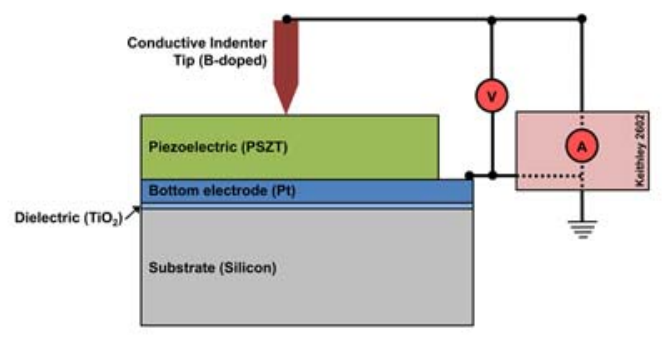

(c)

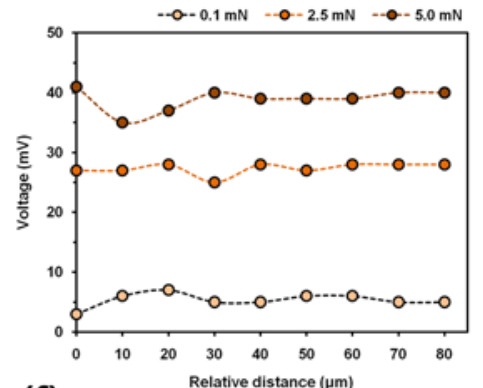

(f) 


\section{Figure 16}

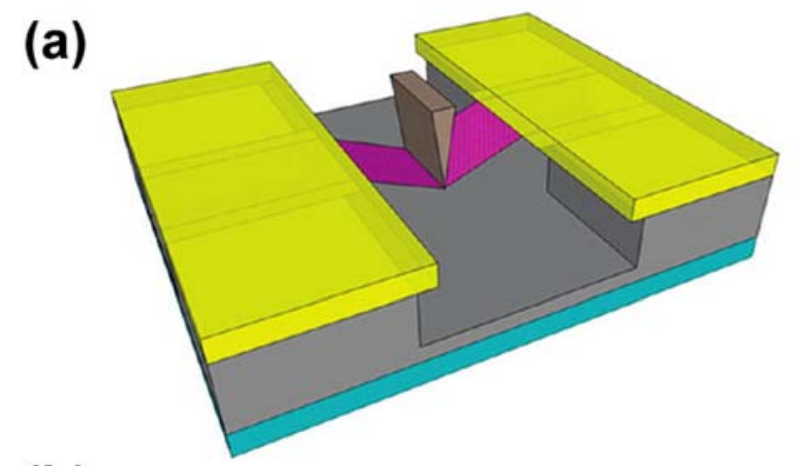

(b)

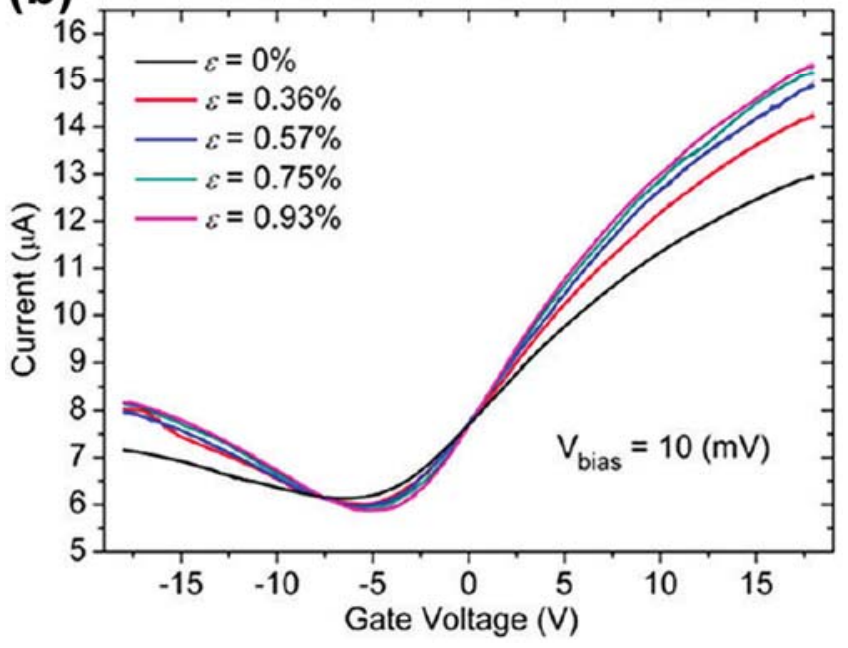




\section{Figure 17}
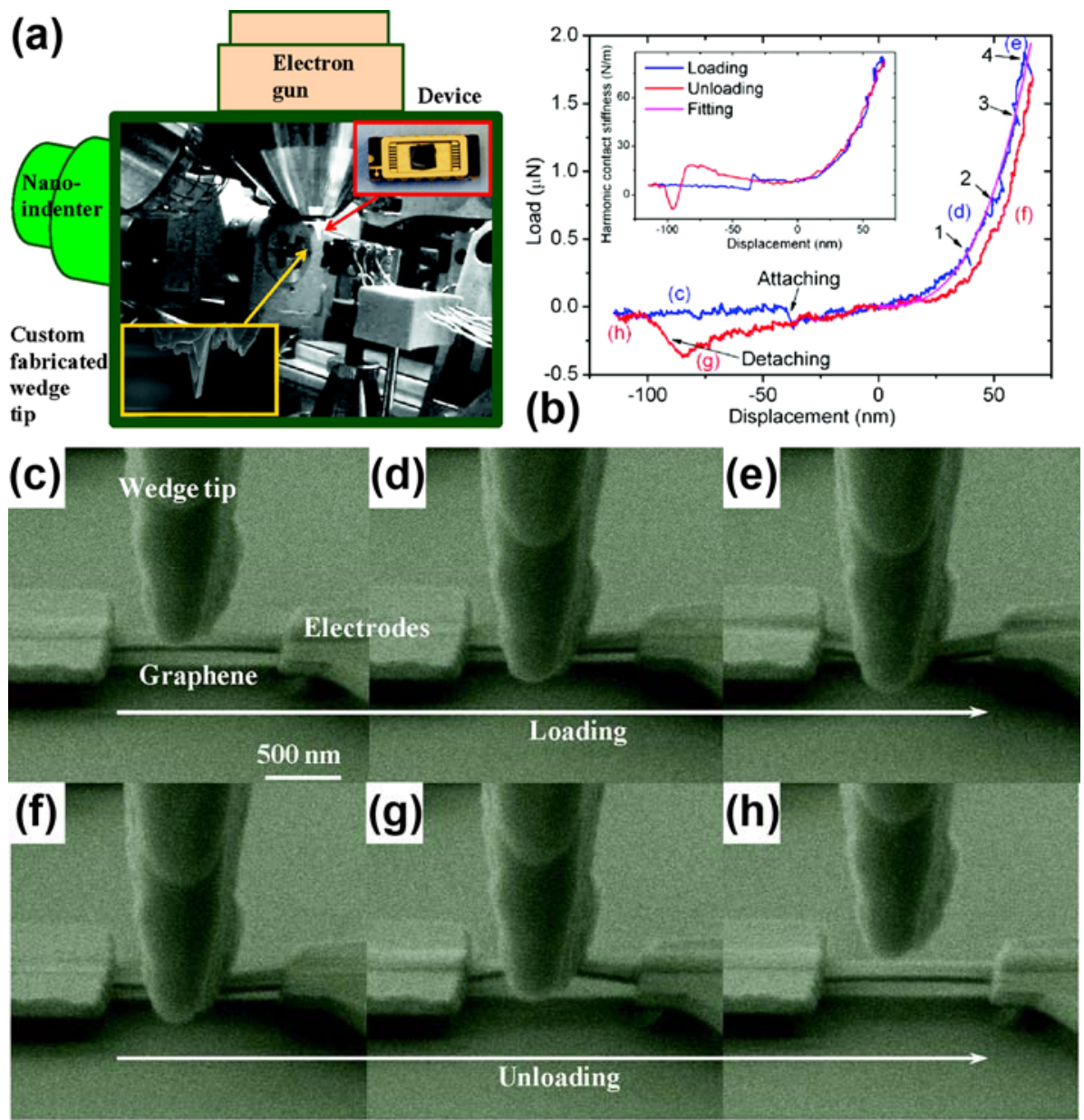
Figure 18
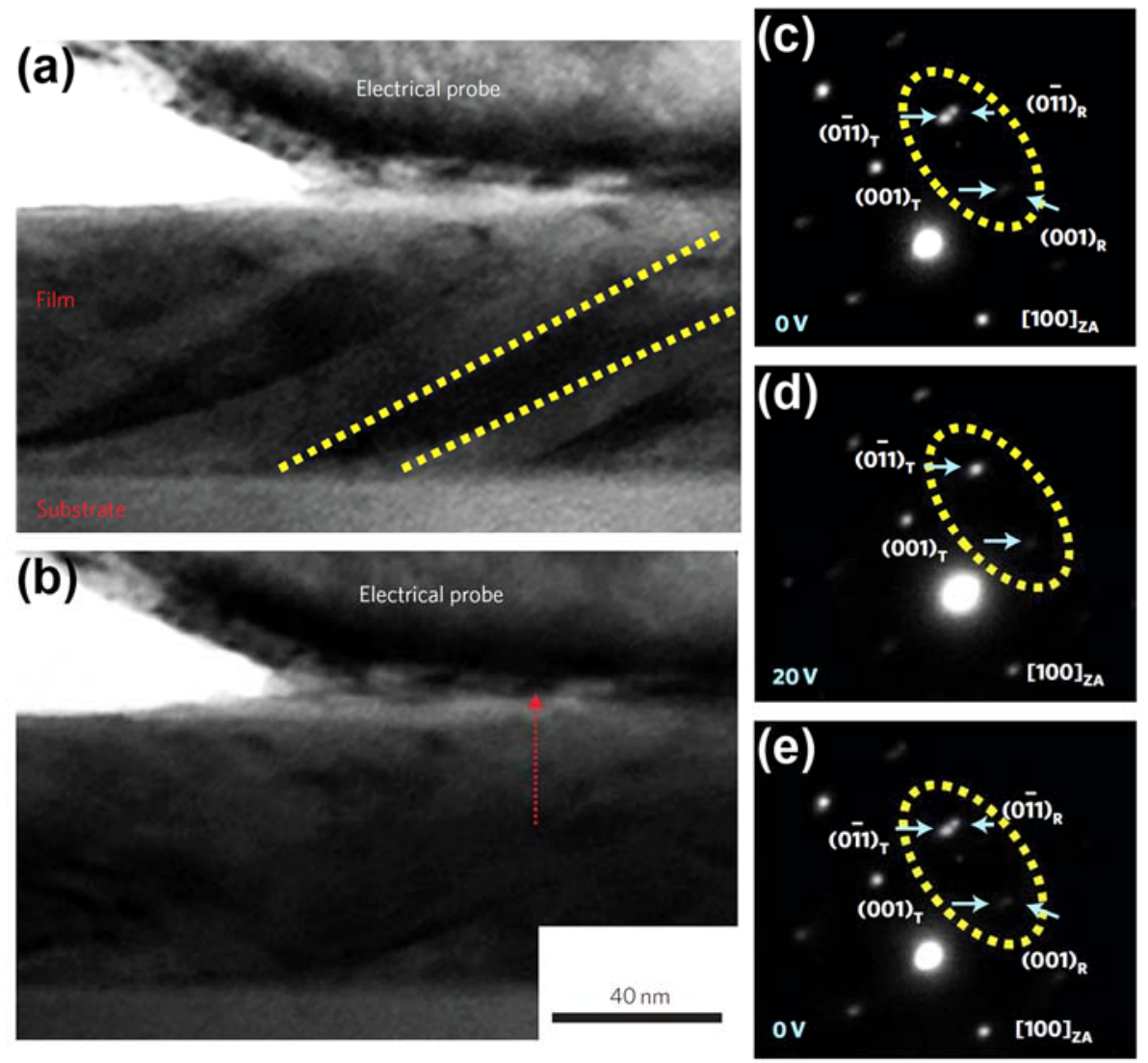
Submitted for Peer-Review to Progress in Materials Science

\section{Figure 19}

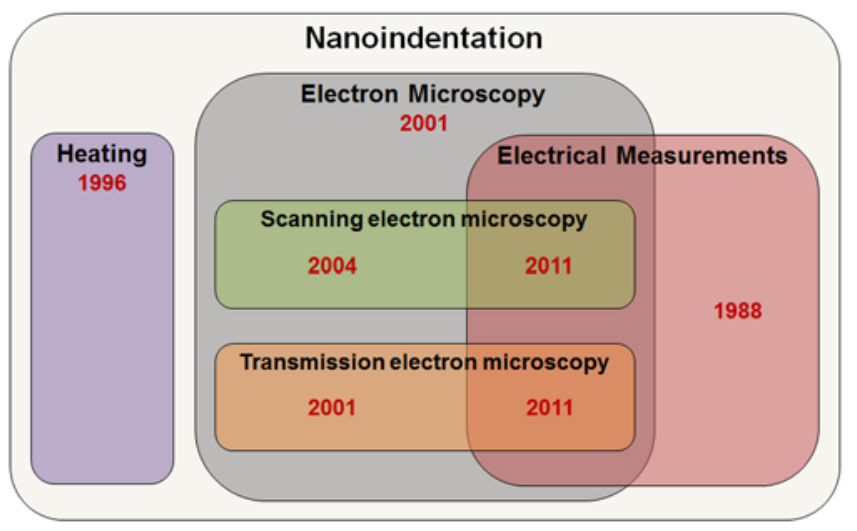

